\title{
Binary mixtures of choline chloride-based deep eutectic solvents as green extractants for the extraction of benzene from $n$-hexane
}

\author{
Mohammed Awwalu Usman ${ }^{1}$ (D) Olumide Kayode Fagoroye ${ }^{1} \cdot$ Toluwalase Olufunmilayo Ajayi $^{1}$. \\ Abiola John Kehinde ${ }^{1}$
}

Received: 14 January 2021 / Accepted: 15 March 2021 / Published online: 24 March 2021

(c) The Author(s) 2021

\begin{abstract}
A suitable green solvent for extraction of aromatics from aliphatics must possess good solvation and physicochemical properties, a rare occurrence in a single deep eutectic solvent (DES). Mixture of DESs could enable synergy and provide a good candidate extractant. In this study, DESs of glyceline, ethaline, and reline were synthesized and their binary mixtures (glyceline/ethaline, reline/ethaline, and glyceline/reline) produced by blending in various volume proportions. Twelve of such mixed solvents were prepared and their extraction efficiency for separating benzene from $n$-hexane investigated in a batch equilibrium process. Liquid-liquid equilibria (LLE) data for the pseudo-ternary systems of $n$-hexane + benzene + mixed DESs were measured at $303 \mathrm{~K}$ and $101.3 \mathrm{kPa}$. The distribution coefficient $(D)$ and selectivity $(S)$ of each pseudo-ternary system were determined to elicit extraction efficiency. The physicochemical properties of the mixed DESs were also measured. The results show that generally the distribution coefficients, selectivities, and physicochemical properties of the mixed DESs lie between the corresponding values for the constituent DES. The best performance was given by the mixed solvent of glyceline and ethaline in the 80:20 volume ratio, respectively, with $D=0.75$ and $S=422.485$. This assertion was further corroborated by higher percent recovery of benzene obtained from the said mixed DES $(57.88 \%)$ relative to other mixed DESs $(\leq 49.11 \%)$ examined in this study. Furthermore, its separation efficiency is superior to sulfolane but lower than glyceline, though there was a $9.4 \%$ reduction in its viscosity relative to glyceline.
\end{abstract}

Keywords Glyceline $\cdot$ Ethaline $\cdot$ Reline $\cdot$ Green solvent $\cdot$ Distribution coefficient $\cdot$ Separation factor $\cdot$ Viscosity

\section{Introduction}

One of the principles of green chemistry (sustainability) encourages the use of environmentally benign solvents in place of the harmful ones [1,2]. In furtherance of this provision, deep eutectic solvents (DESs) have emerged as good replacement for conventional organic solvents and even ionic liquids (ILs), with which it shares similar physicochemical properties [3, 4]. ILs are more expensive, harder to synthesize and less green [3-5]. Though not all DESs can be truly classified as green solvent, a recent comprehensive assessment using multi-criteria such as safety, biodegradability, and toxicological parameters show that Type III DESs, particularly those synthesized using choline chloride

Mohammed Awwalu Usman

musman@unilag.edu.ng; mawwal04@yahoo.com

1 Department of Chemical and Petroleum Engineering, University of Lagos, Akoka, Yaba, Lagos 101017, Nigeria as hydrogen-bond acceptor (HBA) and sugar alcohols (glycerol or ethylene glycol), straight-chain alcohols, sugars, and amides (urea) as hydrogen-bond donor (HBD), are promising environmentally friendly or green solvents [6]. In another study, Lapena et al. [7] investigated the toxicological behavior and biodegradability of glyceline, ethaline, and reline, and their results reveal that these DESs are both biodegradable and have low toxicities. There is increasing interest in the exploration and application of DESs in wide and diverse areas by researcher due to their extremely low vapor pressure, high thermal and chemical stability, non-flammability, high solvation capacity, and cost effectiveness [8, 9]. One area of such application is in liquid-liquid extraction processes where it is used as extracting solvent. To function in this capacity, the DES should have suitable preferential solvency power for the desired solute as measured by two metrics, distribution coefficient $(D)$ and selectivity factor $(S)$. Furthermore, it should have the right physicochemical properties, especially density and viscosity. 
Both ILs and DESs possess higher viscosities relative to the conventional organic solvents; this has limited their industrial application in many areas despite superior performance efficiency. Liquid-liquid extraction of aromatics from aliphatic media using ILs and DESs as extractants has attracted intense research interest due to its relevance to the refineries and petrochemical industries. They show preferential solvency for aromatics as evident in their promising values of distribution coefficient and selectivity, but are challenged by their higher viscosities as compared to the commonly used organic solvent (sulfolane). In our previous contributions, the superiority of glyceline (choline chloride: glycerol in 1:2 molar ratio), ethaline (choline chloride: ethylene glycol in 1:2 molar ratio), and reline (choline chloride:urea in 1:2 molar ratio) over sulfolane was eloquently demonstrated $[10,11]$. However, the viscosities of these DESs at $298 \mathrm{~K}$ are profoundly higher with the following values: glyceline (281 cP) [12], ethaline (42 cP) [13], and reline (750 cP) [14] as against sulfolane (10.35 cP) [15]. One possible way of obtaining solvent with suitable holistic properties (distribution coefficient, selectivity, and physicochemical) is by mixing or blending two or more ILs or DESs.

A number of studies have explored possible synergy either in terms of enhanced solvency or reduction in viscosity. Garcia et al. [16] investigated the extraction of toluene from $n$-heptane using a binary mixture of $N$-butylpyridinium tetrafluoroborate $\left([\mathrm{bpy}]\left[\mathrm{Tf}_{2} \mathrm{~N}\right]\right)$ and $\mathrm{N}$-butylpyridinium bis(trifluoromethylsulfonyl)imide ([bpy] $\left[\mathrm{BF}_{4}\right]$ ) ILs. The results of their work showed that the extractive properties of the binary mixture lie between those of the constituent $\mathrm{IL}$; with the mixture at a mole fraction of $0.7[\mathrm{bpy}]\left[\mathrm{BF}_{4}\right]$ having improved values of distribution coefficient and selectivity over sulfolane and reduced viscosity relative to the constituent ILs. Alkhaldi et al. [17] explored the use of mixed ILs of 1-ethyl-3-methylimidazolium methylsulfate [emim] $\left[\mathrm{CH}_{3} \mathrm{SO}_{4}\right]$ and 1-hexyl-3-methylimidazoliumhexafluorophosphate $[\mathrm{hmim}]\left[\mathrm{PF}_{6}\right]$ in the extraction of toluene from heptanes, octane, or nonane. Their results indicate that the toluene distribution coefficient and selectivity values obtained for the mixed IL with $0.9 \mathrm{~mol}$ fraction of [hmim] $\left[\mathrm{PF}_{6}\right]$ were higher than those of sulfolane. Guo et al. [18] achieved synergy in terms of improved distribution coefficient and selectivity using a mixture of two ILs, namely 1-ethyl-3-methylimidazolium bis(trifluoromethylsulfonyl) imide ([emim] $\left.\left[\mathrm{NTf}_{2}\right]\right)$ and 1-ethyl-3-methylimidazolium ethylsulfate ([emim] $\left.\left[\mathrm{EtSO}_{4}\right]\right)$ to extract benzene from $n$-hexane. In all these studies, the primary consideration was to attain synergy between two ILs in terms of improved distribution coefficient or selectivity, even though viscosity reduction was also achieved.

Similar studies have been carried out for DESs but with the exclusive focus on improving physicochemical properties. A significant decrease in viscosity was reported for the binary mixtures of glyceline:ethaline [19], reline:glyceline [20], and reline:ethaline [21]. To the best of our knowledge, there has not been any study on the effect of mixing DESs on its extraction capacity. Yet, the marked differences between reline, glyceline, and ethaline in their extraction performance for aromatics, as reported in our previous contributions $[10,11]$, suggest a possible synergy for a more suitable extractant.

This study therefore explores the performance of binary mixtures of glyceline, ethaline, and reline as extractants in the separation of aromatics from aliphatics. Specifically, three binary mixtures of glyceline and ethaline, glyceline and reline, and reline and ethaline were prepared in various volume proportions and assessed for the extraction of benzene from $n$-hexane. Distribution coefficient and selectivity for the various pseudo-ternary systems were evaluated to elicit possible synergy, generate liquid-liquid equilibria data for the systems, and determine the most suitable mixed solvent for the extraction process.

\section{Experimental}

\section{Materials}

The materials used for this investigation are same as enumerated in our previous contribution [10]. Benzene, $n$-hexane, choline chloride, ethylene glycol, urea, and glycerol were purchased from Sigma-Aldrich (Germany) with a mass fraction purity higher than 0.98 . All chemicals were used as received without further purification and they were stored in a desiccator in their original tightly closed bottles. Refractive indices of benzene, $n$-hexane, ethylene glycol, glycerol, urea, choline chloride, and DESs were measured via refractometer.

\section{Preparation and mixing of deep eutectic solvents (reline, glyceline, and ethaline)}

Three deep eutectic solvents were prepared in this study, namely reline (choline chloride and urea), glyceline (choline chloride and glycerol), and ethaline (choline chloride and ethylene glycol). Choline chloride was used as the hydrogen-bond acceptor while urea, glycerol and ethylene glycol serve as the hydrogen-bond donors in the molar ratio $1: 2$, respectively. The detailed protocol for preparing these DESs is as explained in our previous article [10]. Binary mixtures of these DESs were then prepared by mixing two pair of DESs in varying volume proportion as listed in Table 1. Four mixed DESs were prepared for each pair (glyceline:ethaline, reline:ethaline, and glyceline:reline), giving a total of twelve (12) mixed DESs. The overall number of DESs used for this 
Table 1 List of the prepared DESs (mono and mixed) for this study

\begin{tabular}{|c|c|}
\hline DES composition (mole ratio) & Code name \\
\hline DES (ChCl:Gly)(1:2) & DES1 \\
\hline DES (ChCl:EG)(1:2) & DES2 \\
\hline DES (ChCl:Ur)(1:2) & DES3 \\
\hline DES $[80 \% \mathrm{ChCl}: \mathrm{Gly}+20 \% \mathrm{ChCl}: \mathrm{EG}](1: 2)$ & DES4 \\
\hline DES $[60 \% \mathrm{ChCl}: \mathrm{Gly}+40 \% \mathrm{ChCl}: \mathrm{EG}](1: 2)$ & DES5 \\
\hline DES [40\%ChCl:Gly + 60\%ChCl:EG] $(1: 2)$ & DES6 \\
\hline DES $[20 \% \mathrm{ChCl}: \mathrm{Gly}+80 \% \mathrm{ChCl}: \mathrm{EG}](1: 2)$ & DES7 \\
\hline DES [80\%ChCl:Ur + 20\%ChCl:EG](1:2) & DES8 \\
\hline DES $[60 \% \mathrm{ChCl}: \mathrm{Ur}+40 \% \mathrm{ChCl}: \mathrm{EG}](1: 2)$ & DES9 \\
\hline DES $[40 \% \mathrm{ChCl}: \mathrm{Ur}+60 \% \mathrm{ChCl}: \mathrm{EG}](1: 2)$ & DES10 \\
\hline DES $[20 \% \mathrm{ChCl}: \mathrm{Ur}+80 \% \mathrm{ChCl}: \mathrm{EG}](1: 2)$ & DES11 \\
\hline DES $[80 \% \mathrm{ChCl}: \mathrm{Gly}+20 \% \mathrm{ChCl}: \mathrm{Ur}](1: 2)$ & DES12 \\
\hline DES $[60 \% \mathrm{ChCl}: \mathrm{Gly}+40 \% \mathrm{ChCl}: \mathrm{Ur}](1: 2)$ & DES13 \\
\hline DES [40\%ChCl:Gly + 60\%ChCl:Ur](1:2) & DES14 \\
\hline DES $[20 \% \mathrm{ChCl}: \mathrm{Gly}+80 \% \mathrm{ChCl}: \mathrm{Ur}](1: 2)$ & DES15 \\
\hline
\end{tabular}

investigation is fifteen (15), 3 single DESs and 12 mixed DESs as presented in Table 1 with their code name.

\section{Extraction and determination of LLE data}

The 12 mixed DESs were each investigated for their extraction capacity; each was used as an extractant in the separation of $n$-hexane + benzene mixture. The extraction process was done on a bench scale as described in our article [10]. Measured volume of $n$-hexane + benzene mixture (feed) was contacted with mixed DES in $250 \mathrm{ml}$ beaker. The extraction runs were carried out in a vessel, the temperature was controlled by a water bath at $303 \mathrm{~K}$. After bringing the feed to extraction temperature, the solvent was added at the same temperature (according to the predetermined ratio). A rotating stainless steel shaft was used for mixing the feed and solvent at a controlled degree of mixing of $500 \mathrm{rpm}$. The extraction was carried out for a predetermined mixing time of $1 \mathrm{~h}$ and the mixture was left to separate into a raffinate phase ( $n$-hexane rich phase) at the top and an extract phase (DES-rich phase) at the bottom for a predetermined settling time of $4 \mathrm{~h}$. The extract was then separated and the equilibrium compositions of the phases were determined.

\section{Extraction or recovery efficiency}

To have a common basis for comparison between the 15 extractants investigated in this study, a feed mixture containing $25 \mathrm{~mol}$ percent benzene and $75 \mathrm{~mol}$ percent $n$-hexane was prepared and contacted with each of the extractant to attain equilibrium. Equal volume of the feed solution and extractant were used in each case and the LLE data determined as described in the previous section. These data were then used to evaluate the percent extraction or recovery of benzene by each of the 15 extractants.

\section{Determination of physicochemical properties}

Densities were measured using a density tube meter, and the viscosities were measured with a Brooksfield DV2T viscometer. This viscometer was calibrated with distilled water. Viscosity of the samples $(\eta)$ was obtained under the following conditions; the flow time of $60 \mathrm{~s}$ was used to measure the flow time in the solvent mixture, $T=303 \mathrm{k}$ and a speed of $50 \mathrm{rpm}$. The estimated uncertainty of the experimental viscosity was $\pm 0.02 \mathrm{cP}$. The refractive index was measured with a digital refractometer (ATAGO DRA1, Japan) with an uncertainty of \pm 0.001 .

The analytical balance (AND, GR202, Japan) with the precision of $\pm 0.0001 \mathrm{~g}$ was used for the preparation of mixtures in molar basis. The studied binary DESs' mixtures were prepared in well-sealed glass vials to avoid contamination or mixture evaporation. Measurements were done continually after the mixtures preparation.

\section{Determination of performance parameters}

The performances of the extractants were evaluated based on three metrics, namely benzene distribution coefficient $(D)$, selectivity $(S)$, and the percent extraction or recovery of benzene $(R)$. These metrics are defined mathematically in Eqs. (1-3):

$D=\frac{x_{23}}{x_{21}}$

$S=\frac{x_{23} \cdot x_{11}}{x_{21} \cdot x_{13}}$

$R=\frac{x_{23} \cdot \frac{\text { mass of extract }}{\text { mol. wt. of extract }}}{0.25 \cdot \frac{\text { mass of feed }}{\text { mol. wt. of feed }}} \cdot 100$,

where $x_{23}$ is the mole fraction of benzene in the extract (DES) phase, $x_{21}$ is the mole fraction of benzene in the raffinate ( $n$-hexane) phase, $x_{13}$ is the mole fraction of $n$-hexane in the extract (DES) phase, and $x_{11}$ is the mole fraction of $n$-hexane in the raffinate (hexane) phase.

\section{Results and discussion}

In this section, the results of the experimental studies and analyses therefrom are presented and thoroughly discussed. The first sub-section presents and explains the performance of the mixed DESs under the banner of the three pairs

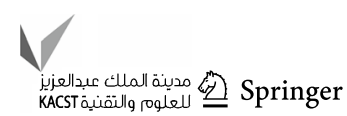


(glyceline/ethaline, reline/ethaline, and glyceline/reline). The percent extraction or recovery of benzene by the 15 DESs is then presented in the second sub-section, while the physicochemical properties of these DESs follow in third sub-section. The section is concluded with a general discussion and comparison of the studied extractants in the fourth sub-section.

\section{Performance of the mixed deep eutectic solvents}

The performance of the three pairs of mixed DESs, glyceline/ethaline, reline/ethaline, and glyceline/reline, is hereby presented.

\section{Glyceline/ethaline mixed DESs}

This sub-section presents the liquid-liquid equilibria data, ternary diagrams, distribution coefficients, and selectivities for the extraction of benzene from $n$-hexane using the mixed DESs of glyceline and ethaline as extractants. It is intended to analyse the effect of ethaline addition on the performance of the mixed DESs relative to neat-glyceline.

LLE data and tie lines Table 2 presents the experimental LLE data for the pseudo-ternary systems of $n$-hexane (1) +benzene (2) + DES (glyceline/ethaline) (3). The tie lines for the various systems with varying volume proportions of glyceline (ChCl:Gly) to ethaline (ChCl:EG) are plotted in Figs. 1, 2,3 and 4. It is clear from these figures that the mixed DES are not miscible with the $n$-hexane, so negligible amount of DES was found in the $n$-hexane phase. The two-phase region also decreases as the volume proportion of ethaline increases from 20\% in Fig. 1 to 80\% in Fig. 4. Type 1 behavior according to Treybal's classification was exhibited by all the four extractants like the neat-glyceline [10]. The highly polar nature of the studied DES may be responsible for its immiscibility with $n$-hexane. Finally, the positive slopes of tie lines show that benzene solubility in $n$-hexane is higher than its solubility in the mixed DES.

Distribution coefficients and selectivities The benzene distribution coefficients $(D)$ obtained for the four pseudoternary systems are presented in Table 2 . Figure 5 shows a plot of $D$ versus benzene composition in the extract phase. DES 4 (20\% ethaline) clearly outperformed others with a marked difference. The other three DESs $(40,60$, and $80 \%$ ethaline) are not significantly apart in performance. For all extractants, $D$ generally increases with increase in the benzene composition in the extract phase.

The selectivity values for the four pseudo-ternary systems are shown in Table 2 and plotted in Fig. 6. Generally, the
Table 2 Experimental LLE data for the pseudo-ternary systems of $n$-hexane (1) + benzene (2) + DES (glyceline/ethaline) (3) at $303 \mathrm{~K}$ and $1 \mathrm{~atm}$

\begin{tabular}{|c|c|c|c|c|c|}
\hline \multicolumn{2}{|c|}{ Raffinate phase } & \multicolumn{2}{|c|}{ Extract phase } & \multirow[t]{2}{*}{$D$} & \multirow[t]{2}{*}{$S$} \\
\hline$x_{11}$ & $x_{21}$ & $x_{13}$ & $x_{23}$ & & \\
\hline \multicolumn{6}{|c|}{$20 \%$ ethaline } \\
\hline 0.8432 & 0.1503 & 0.0013 & 0.0979 & 0.651 & 422.485 \\
\hline 0.7701 & 0.2241 & 0.0098 & 0.1479 & 0.660 & 51.862 \\
\hline 0.7101 & 0.2842 & 0.1251 & 0.2068 & 0.728 & 4.130 \\
\hline 0.6243 & 0.3702 & 0.1444 & 0.2665 & 0.720 & 3.112 \\
\hline 0.5227 & 0.4721 & 0.2015 & 0.3446 & 0.730 & 1.893 \\
\hline 0.4256 & 0.5693 & 0.2199 & 0.4213 & 0.740 & 1.432 \\
\hline 0.3575 & 0.6375 & 0.2489 & 0.4781 & 0.750 & 1.077 \\
\hline \multicolumn{6}{|c|}{$40 \%$ ethaline } \\
\hline 0.8411 & 0.1574 & 0.0045 & 0.0834 & 0.530 & 99.037 \\
\hline 0.8007 & 0.1943 & 0.0115 & 0.103 & 0.530 & 36.909 \\
\hline 0.7206 & 0.2743 & 0.1263 & 0.1509 & 0.550 & 3.139 \\
\hline 0.6133 & 0.3812 & 0.1453 & 0.2135 & 0.560 & 2.364 \\
\hline 0.5175 & 0.477 & 0.2162 & 0.2767 & 0.580 & 1.388 \\
\hline 0.4202 & 0.574 & 0.2285 & 0.3444 & 0.600 & 1.103 \\
\hline 0.3205 & 0.6737 & 0.255 & 0.4042 & 0.600 & 0.754 \\
\hline \multicolumn{6}{|c|}{$60 \%$ ethaline } \\
\hline 0.8768 & 0.1207 & 0.0110 & 0.0640 & 0.530 & 42.265 \\
\hline 0.8115 & 0.1855 & 0.0301 & 0.1020 & 0.550 & 14.824 \\
\hline 0.7288 & 0.2672 & 0.0472 & 0.1496 & 0.560 & 8.645 \\
\hline 0.6553 & 0.3402 & 0.0684 & 0.1973 & 0.580 & 5.556 \\
\hline 0.5975 & 0.3975 & 0.1031 & 0.2345 & 0.590 & 3.419 \\
\hline 0.5055 & 0.4890 & 0.1479 & 0.2934 & 0.600 & 2.051 \\
\hline 0.4590 & 0.5350 & 0.2029 & 0.3264 & 0.610 & 1.380 \\
\hline \multicolumn{6}{|c|}{$80 \%$ ethaline } \\
\hline 0.8750 & 0.1235 & 0.0125 & 0.0630 & 0.510 & 35.709 \\
\hline 0.8001 & 0.1969 & 0.0547 & 0.1044 & 0.530 & 7.756 \\
\hline 0.7240 & 0.2725 & 0.0745 & 0.1472 & 0.540 & 5.250 \\
\hline 0.6645 & 0.3315 & 0.1137 & 0.1757 & 0.530 & 3.098 \\
\hline 0.6113 & 0.3842 & 0.1202 & 0.2152 & 0.560 & 2.849 \\
\hline 0.5680 & 0.4268 & 0.1678 & 0.2433 & 0.570 & 1.930 \\
\hline 0.4300 & 0.5642 & 0.1701 & 0.3272 & 0.580 & 1.466 \\
\hline
\end{tabular}

$S$ decreases with increasing composition of benzene in the extract phase for the four extractants. The maximum value of $S$ decreases with increasing volume percent of ethaline in the mixed DES. The order is DES4 (20\% ethaline, $S=422.485$ ) $>$ DES5 (40\% ethaline, $S=99.037)>$ DES6 $(60 \%$ ethaline, $S=42.265$ ) $>$ DES7 (80\% ethaline, $S=35.709$ ). In comparison with the performance of the mono-DES, DES 1 (glyceline, $S=462.00$ ), and DES2 (ethaline, $S=31.24$ ) as previously presented [10], there is a decrease of $8.55 \%$ in the selectivity of DES4 relative DES1 on account of $20 \%$ ethaline in the former. 
Fig. 1 Experimental tie lines for the system $n$-hexane + benzene + DES 4 [80\%ChCl:Gly + 20\% ChCl:EG] at temperature $303 \mathrm{~K}$ and atmospheric pressure
Fig. 2 Experimental tie lines for the system $n$-hexane + benzene + DES5 [60\% ChCl:Gly + 40\% ChCl:EG] at temperature $303 \mathrm{~K}$ and atmospheric pressure
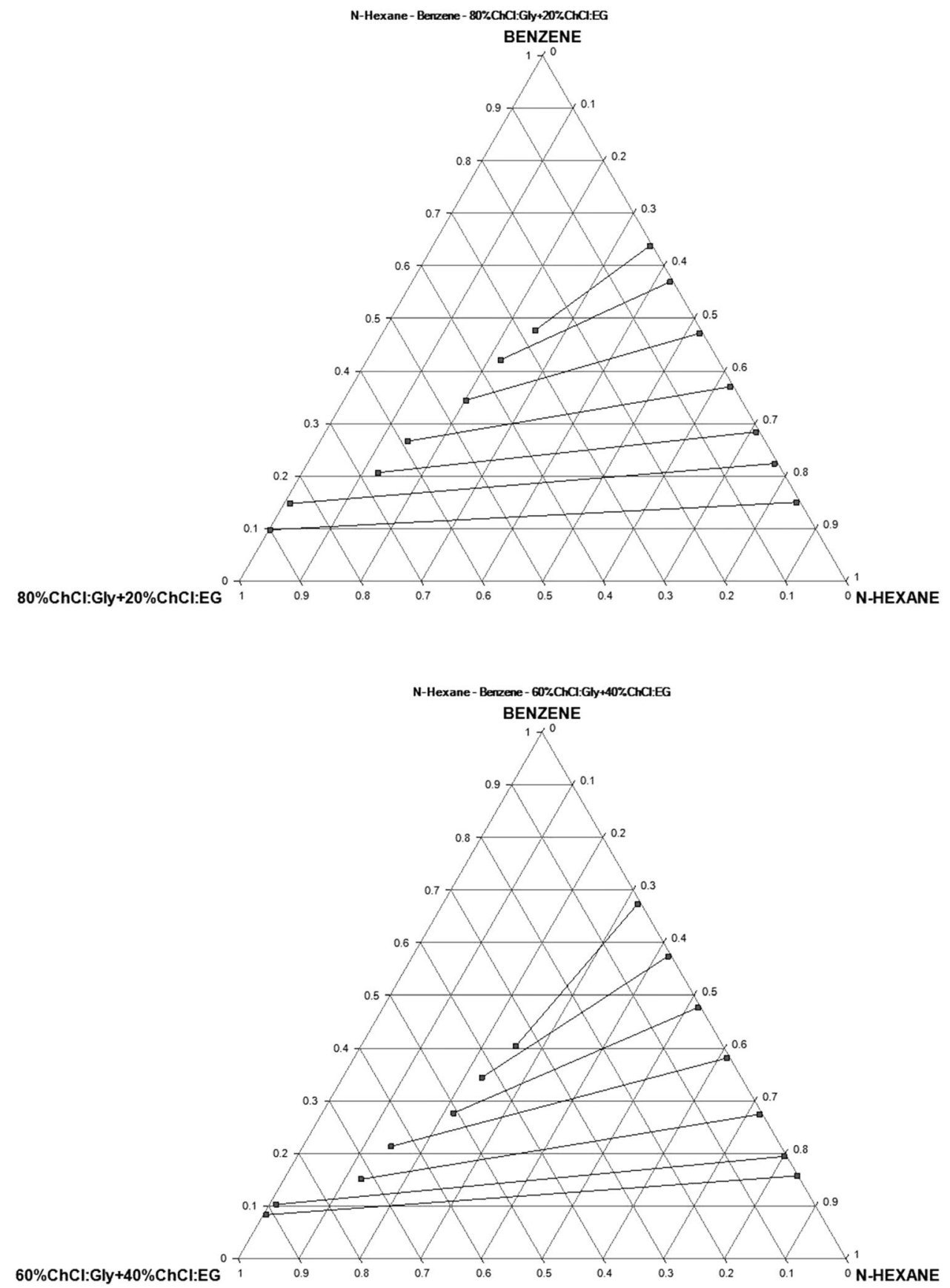

\section{Reline/ethaline mixed DESs}

This sub-section presents the liquid-liquid equilibria data, ternary diagrams, distribution coefficients, and selectivities for the extraction of benzene from $n$-hexane using the mixed DESs of reline and ethaline as extractants. It is intended to analyse the effect of ethaline addition on the performance of the mixed DESs relative to neat-reline.

LLE data and tie lines Table 3 presents the experimental LLE data for the pseudo-ternary systems of $n$-hexane
(1) + benzene (2) + DES (reline/ethaline) (3). The tie lines for the various systems with varying volume proportions of reline $(\mathrm{ChCl}: \mathrm{Ur})$ to ethaline $(\mathrm{ChCl}: \mathrm{EG})$ are plotted in Figs. 7, 8, 9 and 10. It is clear from these figures that the mixed DES are not miscible with the $n$-hexane, so negligible amount of DES was found in the $n$-hexane phase. The two-phase region also decreases as the volume proportion of ethaline increases from 20\% in Fig. 7 to $80 \%$ in Fig. 10. Type 1 behavior according to Treybal's classification was exhibited by all the four extractants like the neat-reline [10]. The highly polar nature of the studied DES may be 
Fig. 3 Experimental tie lines for the system $n$-hexane + benzene + DES6 [40\% ChCl:Gly $+60 \% \mathrm{ChCl}: \mathrm{EG}]$ at temperature $303 \mathrm{~K}$ and atmospheric pressure
Fig. 4 Experimental tie lines for the system $n$-hexane + benzene + DES7 [20\% ChCl:Gly + $80 \% \mathrm{ChCl}: \mathrm{EG}]$ at temperature $303 \mathrm{~K}$ and atmospheric pressure
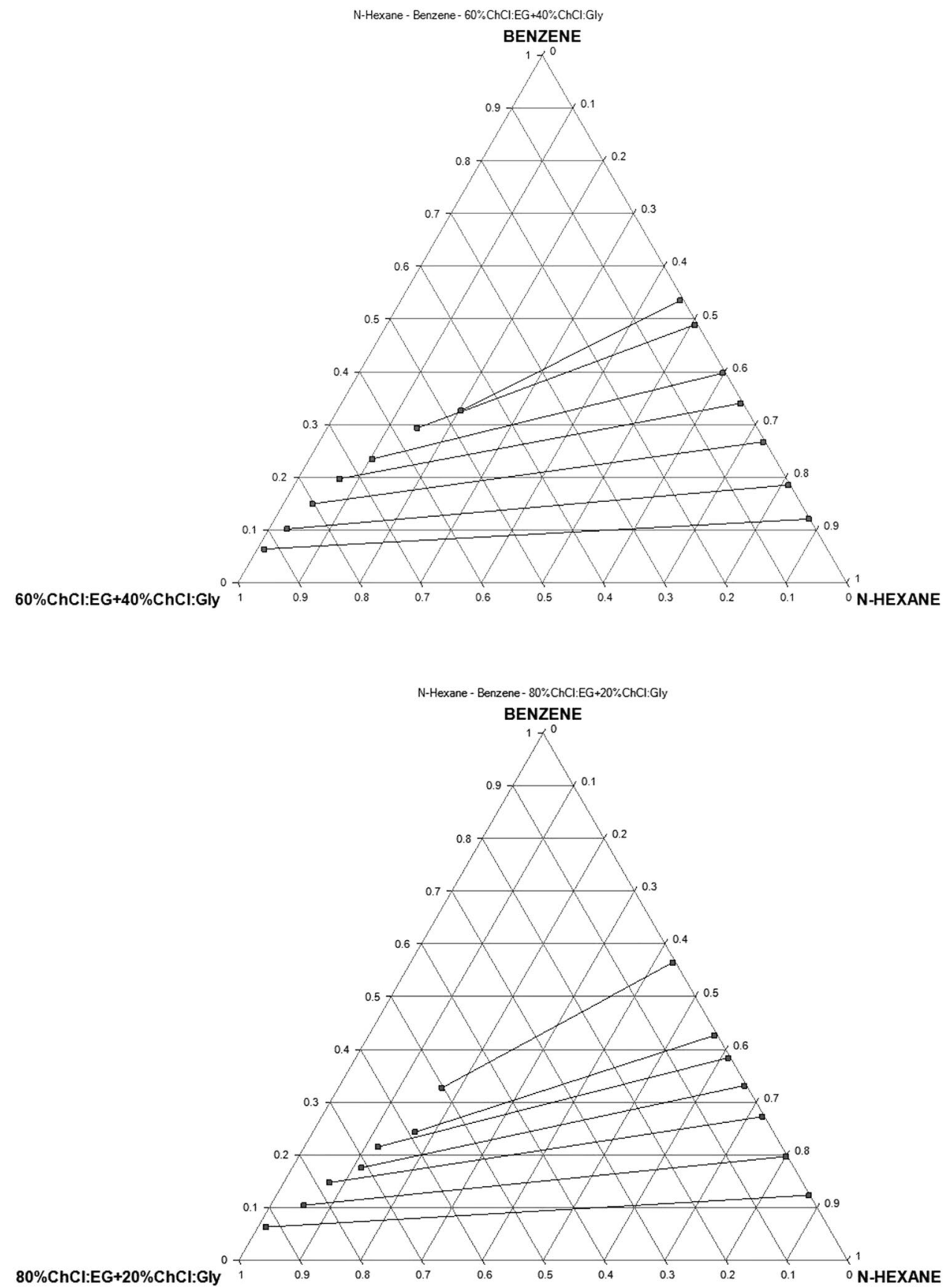

responsible for its immiscibility with $n$-hexane. Finally, the positive slopes of tie lines show that benzene solubility in $n$-hexane is higher than its solubility in the mixed DES.

Distribution coefficients and selectivities The benzene distribution coefficients $(D)$ obtained for the four pseudoternary systems are presented in Table 3 . Figure 11 shows a plot of $D$ versus benzene composition in the extract phase. It is clear that addition of ethaline improved the performance of the mixed DESs relative to neat-reline. The best performance is exhibited by DES11 (80\% ethaline). This is expected considering the performance of the mono-DES (reline, $D=0.35$; ethaline; $D=0.5816$ ) [10].

The selectivity values for the four pseudo-ternary systems are shown in Table 3 and plotted in Fig. 12. Generally, the $S$ decreases with increasing composition of benzene in the extract phase for the four extractants. Addition of ethaline significantly improved the selectivity of the mixed DES relative to neat-reline. The maximum value of $S$ increases with increasing volume percent of ethaline in the mixed DES. The order is DES11 (80\% ethaline, $S=29.452$ ) $>$ DES10 
Fig. 5 Distribution coefficients as a function of benzene composition in the extract phase for the system $n$-hexane + benzene + DES (glyceline/ethaline) at temperature $303 \mathrm{~K}$ and atmospheric pressure

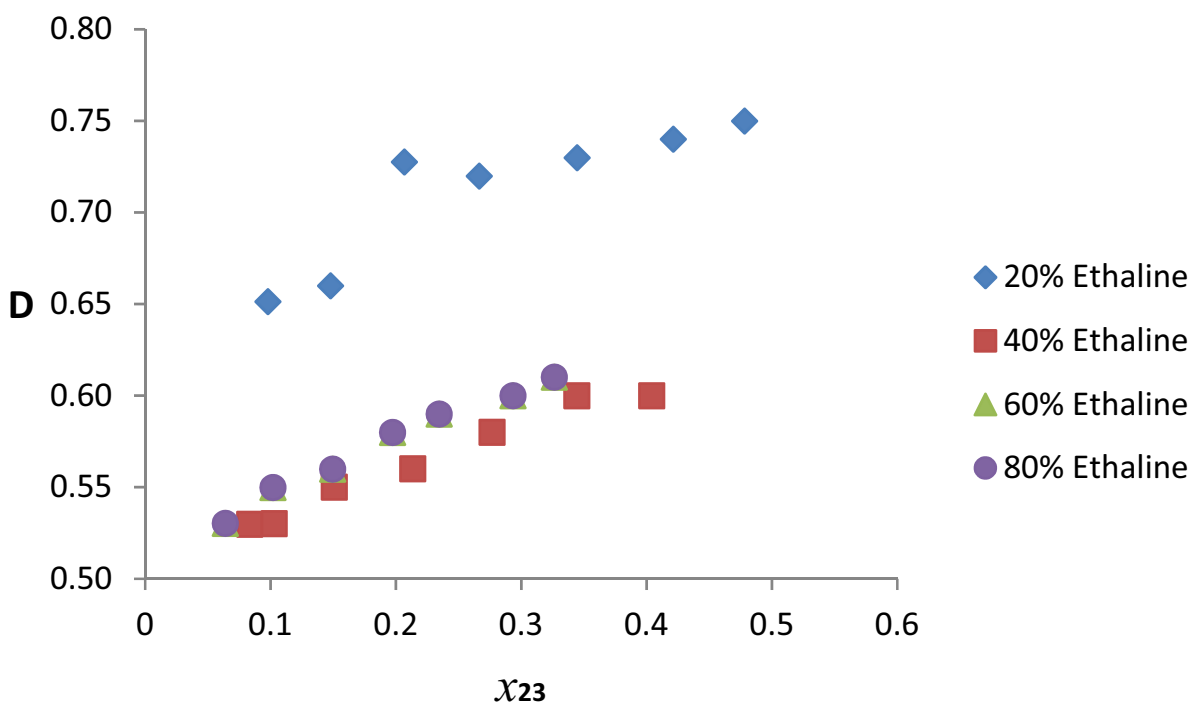

Fig. 6 Selectivity as a function of benzene composition in the extract phase for the system $n$-hexane + benzene + DES (glyceline/ethaline) at temperature $303 \mathrm{~K}$ and atmospheric pressure

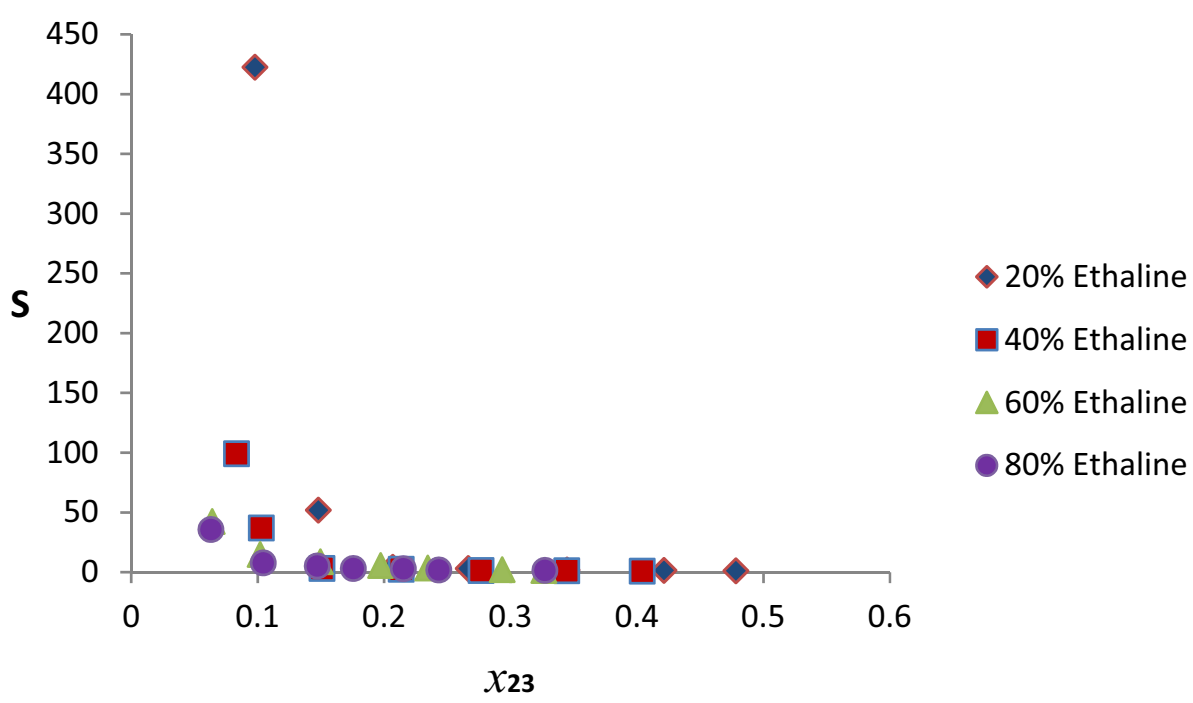

(60\% ethaline, $S=25.683)>$ DES9 (40\% ethaline, $S=$ $21.162)>\operatorname{DES} 8$ (20\% ethaline, $S=17.723)$. The best mixed DES (DES11) in comparison with the performance of the mono-DES, DES3 (reline, $S=15.24$ ), and DES2 (ethaline, $S=31.24$ ) as previously presented [10], there is an increase of $93.25 \%$ in the selectivity of DES11 relative DES3 on account of $80 \%$ ethaline in the former.

\section{Glyceline/reline mixed DESs}

This sub-section presents the liquid-liquid equilibria data, ternary diagrams, distribution coefficients and selectivities for the extraction of benzene from $n$-hexane using the mixed DESs of glyceline and reline as extractants. It is intended to analyse the effect of reline addition on the performance of the mixed DESs relative to neat-glyceline.
LLE data and tie line Table 4 presents the experimental LLE data for the pseudo-ternary systems of $n$-hexane (1)+benzene (2) + DES (glyceline/reline) (3). The tie lines for the various systems with varying volume proportions of glyceline ( $\mathrm{ChCl}$ : Gly) to reline ( $\mathrm{ChCl}: \mathrm{Ur})$ are plotted in Figs. 13, 14,15 and 16. It is clear from these figures that the mixed DES are not miscible with the $n$-hexane, so negligible amount of DES was found in the $n$-hexane phase. The twophase region also decreases as the volume proportion of reline increases from $20 \%$ in Fig. 13 to $80 \%$ in Fig. 16. Type 1 behavior according to Treybal's classification was exhibited by all the four extractants like the neat-glyceline [10]. The highly polar nature of the studied DES may be responsible for its immiscibility with $n$-hexane. Finally, the positive slopes of tie lines show that benzene solubility in $n$-hexane is higher than its solubility in the mixed DES. 
Table 3 Experimental LLE data for the pseudo-ternary systems of $n$-hexane (1) + benzene (2) + DES (reline/ethaline) (3) at $303 \mathrm{~K}$ and $1 \mathrm{~atm}$

\begin{tabular}{|c|c|c|c|c|c|}
\hline \multicolumn{2}{|c|}{ Raffinate phase } & \multicolumn{2}{|c|}{ Extract phase } & \multirow[t]{2}{*}{$D$} & \multirow[t]{2}{*}{$S$} \\
\hline$x_{11}$ & $x_{21}$ & $x_{13}$ & $x_{23}$ & & \\
\hline \multicolumn{6}{|c|}{$20 \%$ ethaline } \\
\hline 0.8226 & 0.1754 & 0.0095 & 0.0359 & 0.205 & 17.723 \\
\hline 0.7101 & 0.2874 & 0.0116 & 0.0632 & 0.220 & 13.461 \\
\hline 0.6245 & 0.3720 & 0.0165 & 0.0893 & 0.240 & 9.086 \\
\hline 0.5770 & 0.4185 & 0.0287 & 0.1046 & 0.250 & 5.025 \\
\hline 0.5196 & 0.4764 & 0.0410 & 0.1191 & 0.250 & 3.168 \\
\hline 0.4683 & 0.5262 & 0.0694 & 0.1473 & 0.280 & 1.889 \\
\hline 0.4218 & 0.5722 & 0.1285 & 0.1831 & 0.320 & 1.050 \\
\hline \multicolumn{6}{|c|}{$40 \%$ ethaline } \\
\hline 0.8335 & 0.1640 & 0.0122 & 0.0508 & 0.310 & 21.162 \\
\hline 0.7541 & 0.2424 & 0.0199 & 0.0800 & 0.330 & 12.506 \\
\hline 0.6822 & 0.3138 & 0.0327 & 0.1067 & 0.340 & 7.094 \\
\hline 0.6088 & 0.3862 & 0.0585 & 0.1352 & 0.350 & 3.643 \\
\hline 0.5360 & 0.4585 & 0.0906 & 0.1605 & 0.350 & 2.071 \\
\hline 0.4725 & 0.5215 & 0.0987 & 0.1721 & 0.330 & 1.580 \\
\hline 0.4110 & 0.5825 & 0.1334 & 0.2155 & 0.370 & 1.140 \\
\hline \multicolumn{6}{|c|}{$60 \%$ ethaline } \\
\hline 0.8510 & 0.1470 & 0.0126 & 0.0559 & 0.380 & 25.683 \\
\hline 0.7664 & 0.2311 & 0.0206 & 0.0924 & 0.400 & 14.875 \\
\hline 0.7175 & 0.2795 & 0.0319 & 0.1146 & 0.410 & 9.222 \\
\hline 0.6446 & 0.3519 & 0.0527 & 0.1478 & 0.420 & 5.137 \\
\hline 0.5943 & 0.4007 & 0.0731 & 0.1643 & 0.410 & 3.334 \\
\hline 0.5005 & 0.4935 & 0.1125 & 0.2073 & 0.420 & 1.869 \\
\hline 0.4277 & 0.5658 & 0.1506 & 0.2490 & 0.440 & 1.250 \\
\hline \multicolumn{6}{|c|}{$80 \%$ ethaline } \\
\hline 0.8650 & 0.1335 & 0.0132 & 0.0600 & 0.449 & 29.452 \\
\hline 0.7880 & 0.2095 & 0.0212 & 0.0964 & 0.460 & 17.103 \\
\hline 0.7225 & 0.2745 & 0.0300 & 0.1318 & 0.480 & 11.564 \\
\hline 0.6672 & 0.3288 & 0.0432 & 0.1644 & 0.500 & 7.722 \\
\hline 0.5715 & 0.4240 & 0.0629 & 0.2035 & 0.480 & 4.361 \\
\hline 0.4650 & 0.5295 & 0.1038 & 0.2542 & 0.480 & 2.151 \\
\hline 0.4116 & 0.5824 & 0.1473 & 0.2854 & 0.490 & 1.369 \\
\hline
\end{tabular}

Distribution coefficients and selectivities The benzene distribution coefficients $(D)$ obtained for the four pseudoternary systems are presented in Table 4 . Figure 17 shows a plot of $D$ versus benzene composition in the extract phase. It is clear that addition of reline attenuated the performance of the mixed DESs relative to neat-glyceline. The best performance is exhibited by DES12 (20\% reline). This is expected considering the performance of the mono-DES (glyceline, $\mathrm{D}=0.91$; reline, $D=0.35$ ) [10]. DES12 (20\% reline) show a remarkably higher values of $D$ compared with the other three mixed DESs (DES13, DES14, DES15). However, there is no significant difference among the latter in their $\mathrm{D}$ values.

The selectivity values for the four pseudo-ternary systems are shown in Table 4 and plotted in Fig. 18. Generally, the $S$ decreases with increasing composition of benzene in the extract phase for the four extractants. Addition of reline significantly attenuated the selectivity of the mixed DES relative to neat-glyceline. The maximum value of $S$ decreases with increasing volume percent of reline in the mixed DES. The order is DES12 (20\% reline, $S=386.538)$ $>$ DES13 (40\% reline, $S=107.373)>$ DES 14 (60\% reline, $S=45.966)>\operatorname{DES} 15(80 \%$ reline, $S=20.351)$. The best mixed DES (DES12) in comparison with the performance of the mono-DES, DES1 (glyceline, $S=462.00$ ), and DES3 (reline, $S=15.24$ ) as previously presented [10], there is a decrease of $16.33 \%$ in the selectivity of DES 12 relative DES 1 on account of $20 \%$ reline in the former.

\section{Extraction or recovery efficiency}

Figure 19 shows the percent recovery of benzene from a common feed composition of $25 \mathrm{~mol} \%$ benzene and $75 \mathrm{~mol} \% n$-hexane using each of the $15 \mathrm{DESs}$ as extractant. The highest percent recovery of benzene was obtained using neat-glyceline (DES1) with a value of $74.58 \%$. Among the mixed DESs, those containing $80 \%$ glyceline gave the highest performance (DES4 and DES12. DES4 gave a percent benzene recovery of $57.88 \%$, while DES12 gave a recovery of $49.11 \%$. The percent recovery or extraction efficiency, considered to be a fair basis for comparison, thus gave results that are in agreement with the maximum values of selectivity. Apparently, only $20 \%$ by volume of either ethaline or reline could be added to glyceline for possible improvement in physicochemical properties considering the drop in extraction performance.

\section{Physicochemical properties of mixed DESs}

The physicochemical properties (density, viscosity, and refractive index) of the studied DESs as measured experimentally are presented and discussed in this section. The intention is to find justification for mixing DESs in terms of improved properties, particularly reduction in viscosity, achieved by any of the mixed pairs. The high viscosity of DESs relative to organic solvents is the singular encumbrance to its gaining traction in the industries. Considering that ethaline has a relatively low viscosity compared to glyceline and reline, it was reasoned that a blend of any of the latter with the former should produce a hybrid DES with reduced viscosity. The various pairs are examined in this section. 


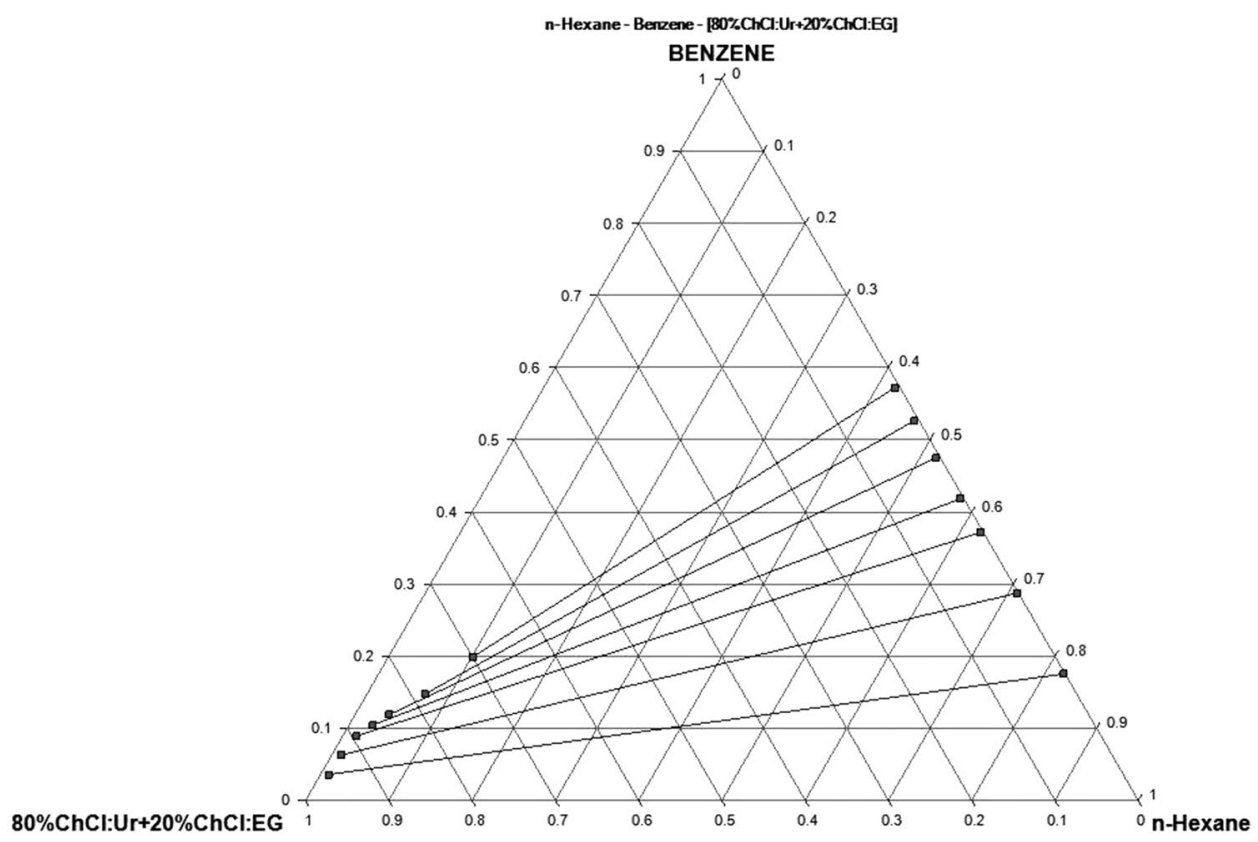

Fig. 7 Experimental tie lines for the system of $n$-hexane + benzene $+[80 \% \mathrm{ChCl}: \mathrm{Ur}+20 \% \mathrm{ChCl}: \mathrm{EG}]$ at temperature $303 \mathrm{~K}$ and atmospheric pressure

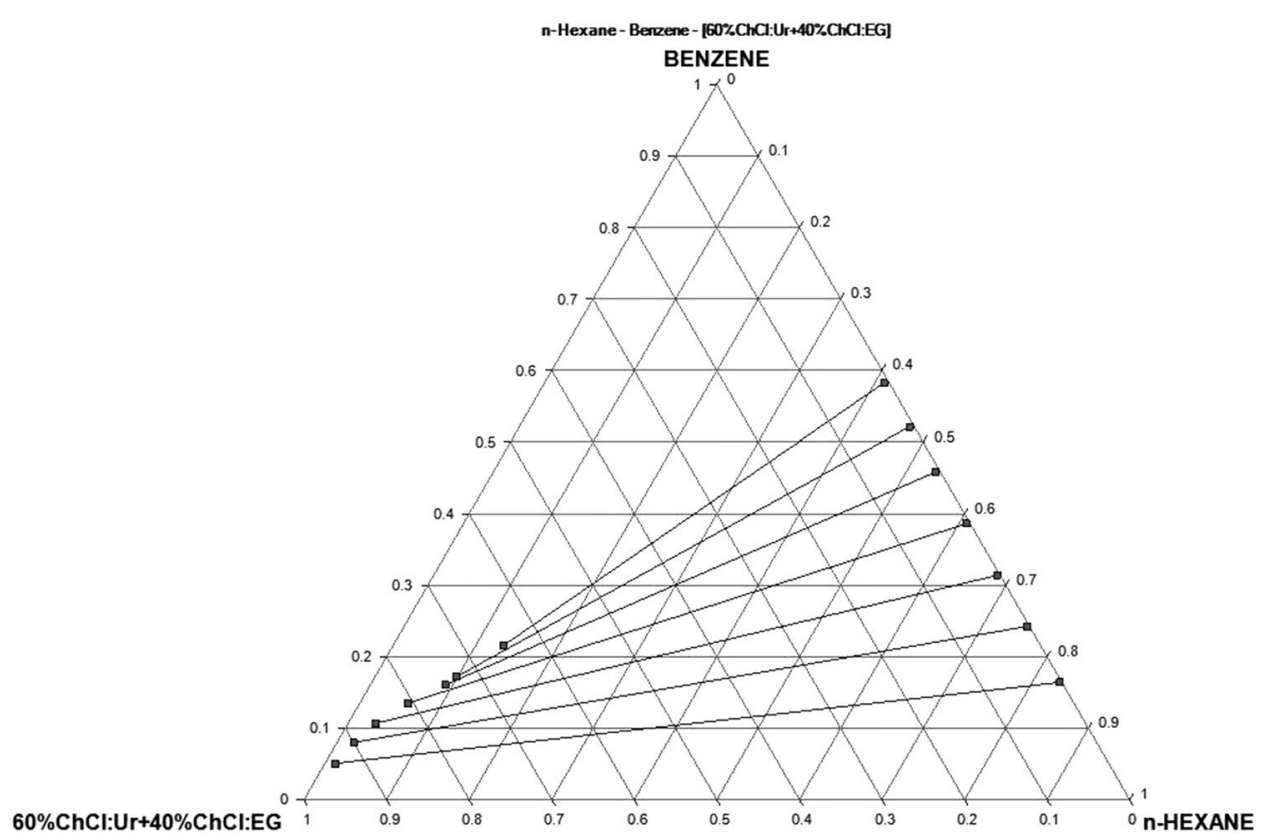

Fig. 8 Experimental tie lines for the system $n$-hexane + benzene $+[60 \% \mathrm{ChCl}: \mathrm{Ur}+40 \% \mathrm{ChCl}: \mathrm{EG}]$ at temperature $303 \mathrm{~K}$ and atmospheric pressure 


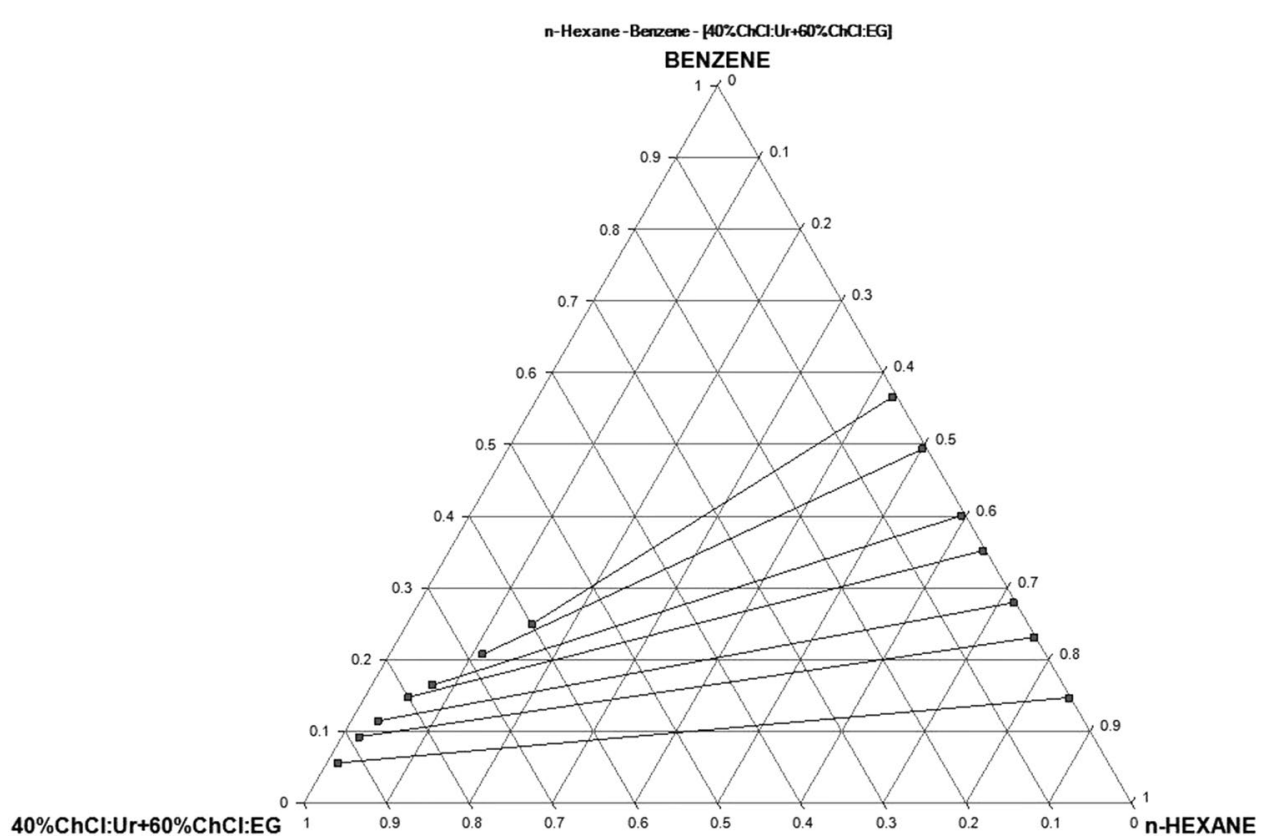

Fig. 9 Experimental tie lines for the system $n$-hexane + benzene $+[40 \% \mathrm{ChCl}: \mathrm{Ur}+60 \% \mathrm{ChCl}: \mathrm{EG}]$ at temperature $303 \mathrm{~K}$ and atmospheric pressure

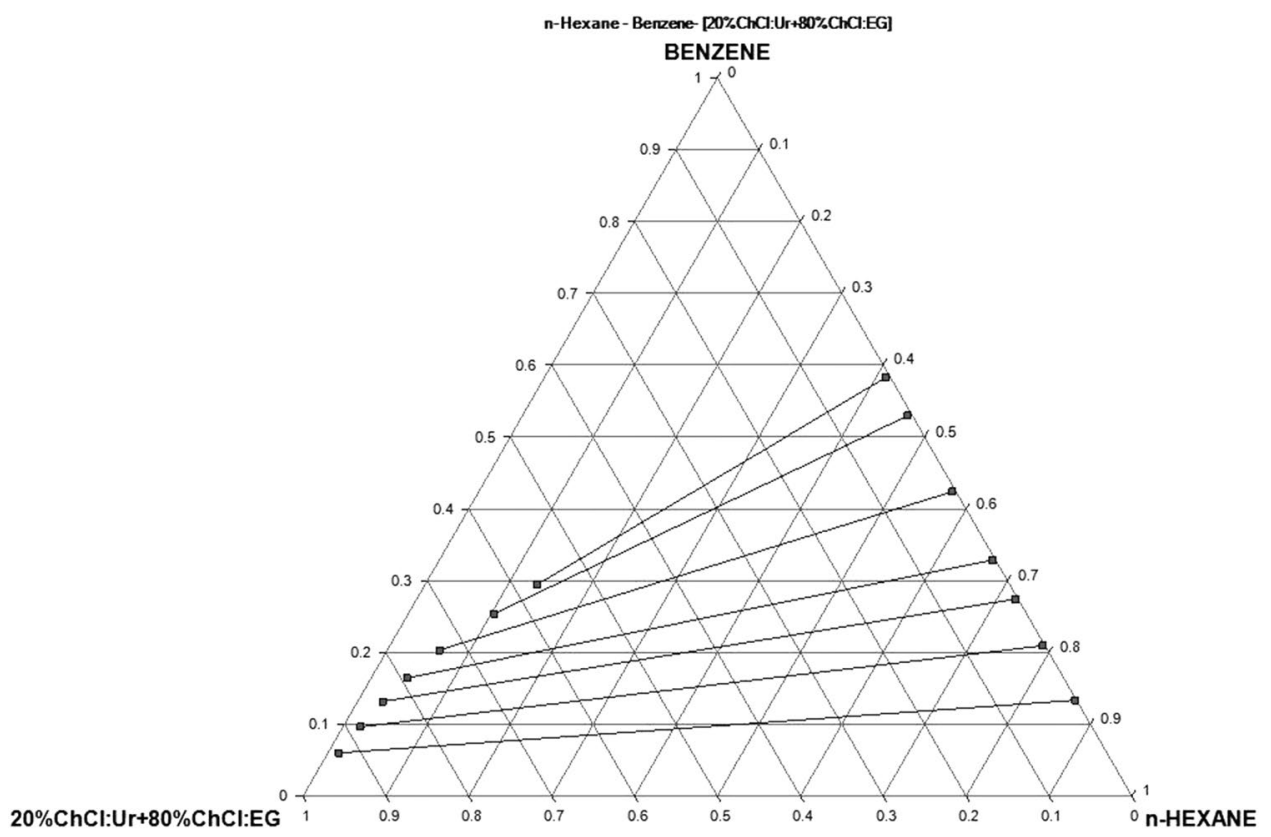

Fig. 10 Experimental tie lines for the system $n$-hexane + benzene $+[20 \% \mathrm{ChCl}: \mathrm{Ur}+80 \% \mathrm{ChCl}: \mathrm{EG}]$ at temperature $303 \mathrm{~K}$ and atmospheric pressure 
Fig. 11 Distribution coefficients as a function of benzene composition in the extract phase for the system $n$-hexane + benzene + DES (reline/ethaline) at temperature $303 \mathrm{~K}$ and atmospheric pressure
Fig. 12 Selectivity as a function of benzene composition in the extract phase for the system $n$-hexane + benzene + DES (reline/ethaline) at temperature $303 \mathrm{~K}$ and atmospheric pressure
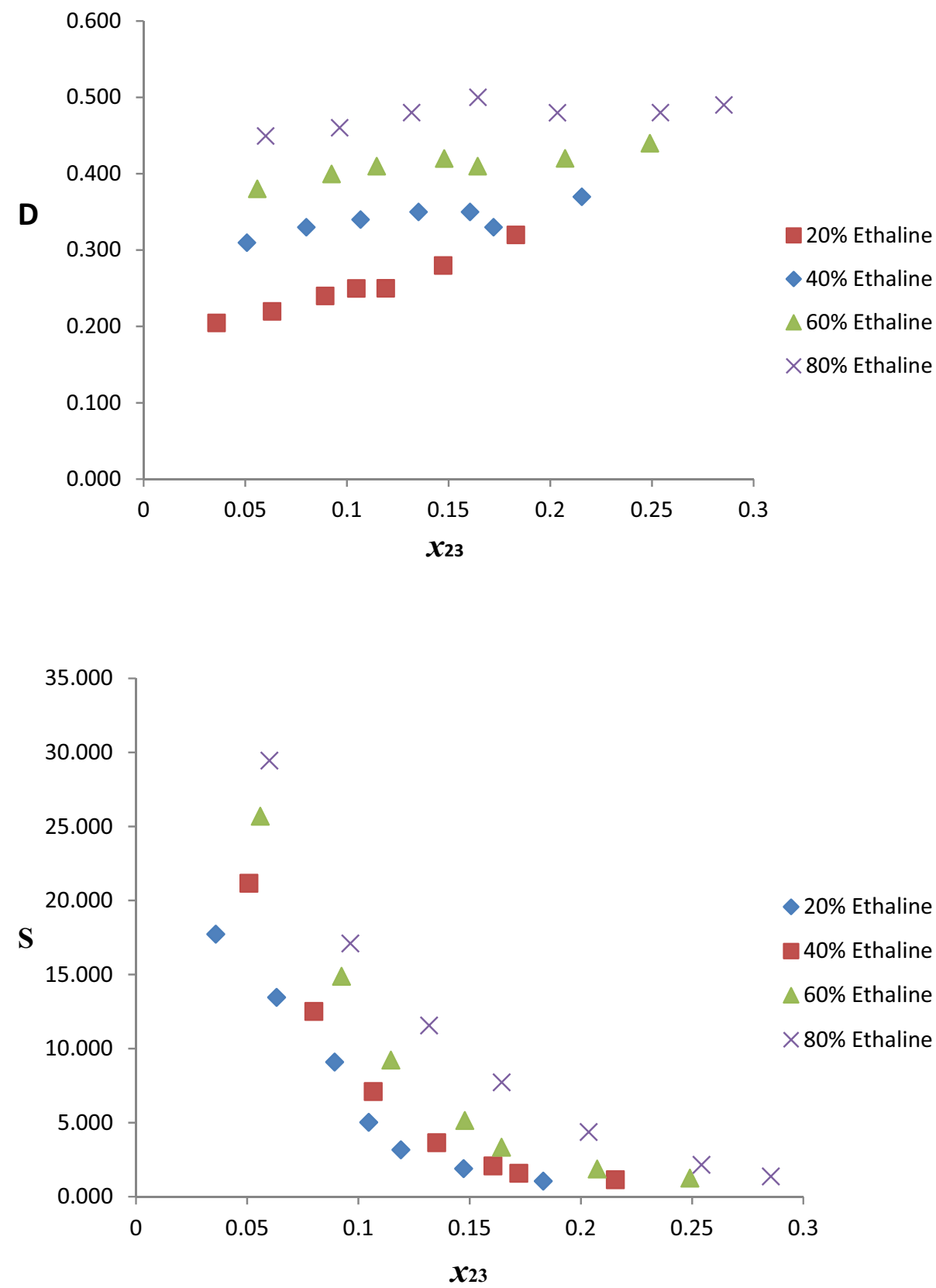

\section{Glyceline/ethaline}

Table 5 shows the density, viscosity, and refractive index of the mixed DESs (glyceline/ethaline) as a function of volume $\%$ of ethaline in the hybrid solvent. These values are plotted in Fig. 20. A significant decrease in viscosity of the mixed DESs is noticed as volume \% of ethaline increases. This is evident from the sharp negative slope of viscosity profile in Fig. 20 and it is in agreement with the findings of previous work in this regard [19]. For example, a decrease of $9.41 \%$ in viscosity was achieved with $20 \%$ addition of ethaline. The profile for density also shows decrease with increasing volume \% ethaline in the mixed DESs but not as sharp as viscosity. On the other hand, the refractive index shows almost constant values with increasing volume $\%$ of ethaline in the mixed DESs.

\section{Reline/ethaline}

Table 6 and Fig. 21 show the density, viscosity, and refractive index of the mixed DESs (reline/ethaline) as a function of volume $\%$ of ethaline in the hybrid solvent. A significant decrease in viscosity of the mixed DESs is noticed as volume $\%$ of ethaline increases. This is evident from the 
Table 4 Experimental LLE data for the pseudo-ternary systems of $n$-hexane (1)+benzene (2)+DES (glyceline/reline) (3) at $303 \mathrm{~K}$ and $1 \mathrm{~atm}$

\begin{tabular}{|c|c|c|c|c|c|}
\hline \multicolumn{2}{|c|}{ Raffinate phase } & \multicolumn{2}{|c|}{ Extract phase } & \multirow[t]{2}{*}{$D$} & \multirow[t]{2}{*}{$S$} \\
\hline$x_{11}$ & $x_{21}$ & $x_{13}$ & $x_{23}$ & & \\
\hline \multicolumn{6}{|c|}{$20 \%$ reline } \\
\hline 0.8375 & 0.1605 & 0.0013 & 0.0963 & 0.600 & 386.538 \\
\hline 0.7450 & 0.2520 & 0.0039 & 0.1562 & 0.620 & 118.406 \\
\hline 0.6387 & 0.3578 & 0.0099 & 0.2505 & 0.700 & 45.168 \\
\hline 0.5062 & 0.4893 & 0.0217 & 0.3327 & 0.680 & 15.861 \\
\hline 0.4215 & 0.5735 & 0.0483 & 0.4015 & 0.700 & 6.109 \\
\hline 0.3481 & 0.6459 & 0.0625 & 0.4521 & 0.700 & 3.898 \\
\hline 0.2970 & 0.6965 & 0.1045 & 0.4925 & 0.707 & 2.010 \\
\hline \multicolumn{6}{|c|}{$40 \%$ reline } \\
\hline 0.8050 & 0.1935 & 0.0021 & 0.0542 & 0.280 & 107.373 \\
\hline 0.7682 & 0.2293 & 0.0052 & 0.0758 & 0.331 & 48.836 \\
\hline 0.6914 & 0.3051 & 0.0060 & 0.1068 & 0.350 & 40.337 \\
\hline 0.6011 & 0.3949 & 0.0069 & 0.1422 & 0.360 & 31.370 \\
\hline 0.5345 & 0.4605 & 0.0106 & 0.1704 & 0.370 & 18.659 \\
\hline 0.4545 & 0.5400 & 0.0224 & 0.2052 & 0.380 & 7.710 \\
\hline 0.3106 & 0.6834 & 0.0661 & 0.2734 & 0.400 & 1.880 \\
\hline \multicolumn{6}{|c|}{$60 \%$ reline } \\
\hline 0.8090 & 0.1880 & 0.0044 & 0.0470 & 0.250 & 45.966 \\
\hline 0.7155 & 0.2805 & 0.0100 & 0.0982 & 0.350 & 25.049 \\
\hline 0.6444 & 0.3506 & 0.0120 & 0.1262 & 0.360 & 19.330 \\
\hline 0.5960 & 0.3985 & 0.0146 & 0.1474 & 0.370 & 15.099 \\
\hline 0.5125 & 0.4815 & 0.0165 & 0.1830 & 0.380 & 11.805 \\
\hline 0.4331 & 0.5599 & 0.0201 & 0.2128 & 0.380 & 8.189 \\
\hline 0.3543 & 0.6392 & 0.0417 & 0.2493 & 0.390 & 3.314 \\
\hline \multicolumn{6}{|c|}{$80 \%$ reline } \\
\hline 0.8130 & 0.1845 & 0.0076 & 0.0351 & 0.190 & 20.351 \\
\hline 0.7018 & 0.2957 & 0.0157 & 0.0976 & 0.330 & 14.754 \\
\hline 0.6314 & 0.3656 & 0.0177 & 0.1243 & 0.340 & 12.128 \\
\hline 0.5400 & 0.4560 & 0.0189 & 0.1459 & 0.320 & 9.142 \\
\hline 0.4813 & 0.5142 & 0.0230 & 0.1748 & 0.340 & 7.114 \\
\hline 0.4163 & 0.5787 & 0.0273 & 0.2025 & 0.350 & 5.336 \\
\hline 0.3346 & 0.6599 & 0.0306 & 0.2294 & 0.348 & 3.801 \\
\hline
\end{tabular}

sharp negative slope of viscosity profile in Fig. 21 and it is in agreement with the findings of previous work in this regard [21]. For example, a decrease of $16.35 \%$ in viscosity was achieved with $20 \%$ addition of ethaline. The profile for density also shows decrease with increasing volume \% ethaline in the mixed DESs but not as sharp as viscosity. On the other hand, the refractive index shows almost constant values with increasing volume $\%$ of ethaline in the mixed DESs.

\section{Glyceline/reline}

Table 7 and Fig. 22 show the density, viscosity, and refractive index of the mixed DESs (glyceline/reline) as a function of volume \% of reline in the hybrid solvent. Considering that the viscosity of reline is higher than that of glyceline, an increase in viscosity of the mixed DESs is expected as volume $\%$ of reline increases. This is evident from the sharp positive slope of viscosity profile in Fig. 22 and it is in agreement with the findings of previous work in this regard [20]. For example, an increase of $10.04 \%$ in viscosity was achieved with $20 \%$ addition of reline. The profiles for density and refractive index remain largely insensitive to increasing volume \% reline in the mixed DESs.

\section{General discussion and comparative analysis}

Bearing in mind the drive of this study, it is instructive to establish the suitability of mixed DESs for extracting benzene from $n$-hexane and compare the performances of one pair of mixed DESs against another on one hand and against sulfolane on the other hand. The foregoing results and analyses show that the binary mixtures of DESs (glyceline/ethaline, reline/ethaline, and glyceline/reline) essentially follow the ideal mixing rule as properties of the mixed DESs lie between those of the constituent neat-DES according to their volume proportions [22-25]. In tandem with the performances of the neat-DES, glyceline impart improved extraction performance in its mixture with reline or ethaline, while ethaline impart reduced viscosity in its mixture with glyceline or reline. Accordingly, binary DESs of glyceline/ethaline have the highest selectivities and distribution coefficients compared to the other two pairs. The order of performance for similar volume proportion is as follows: glyceline/ethaline $>$ glyceline/reline $>$ reline/ethaline. On this account, all mixed DESs are suitable extractant for separating benzene from $n$-hexane, since their selectivities are greater than 1 . On the other hand, mixed DESs with ethaline have the lowest viscosity, with the following order for similar volume proportion: glyceline/reline $>$ reline/ ethaline $>$ glyceline/ethaline. An undesirable decrease in the extraction performance of the mixed DESs was noticed but with a much desired decrease in viscosity, especially for glyceline/ethaline and reline/ethaline. It is not advisable to mix glyceline and reline as it results in both undesired drop in extraction efficiency and increased viscosity. The best mixed DES is the glyceline/ethaline with $20 \%$ volume of ethaline (DES4), with a drop of $8.55 \%$ in selectivity and a decrease of $9.41 \%$ in viscosity relative to neat-glyceline. 


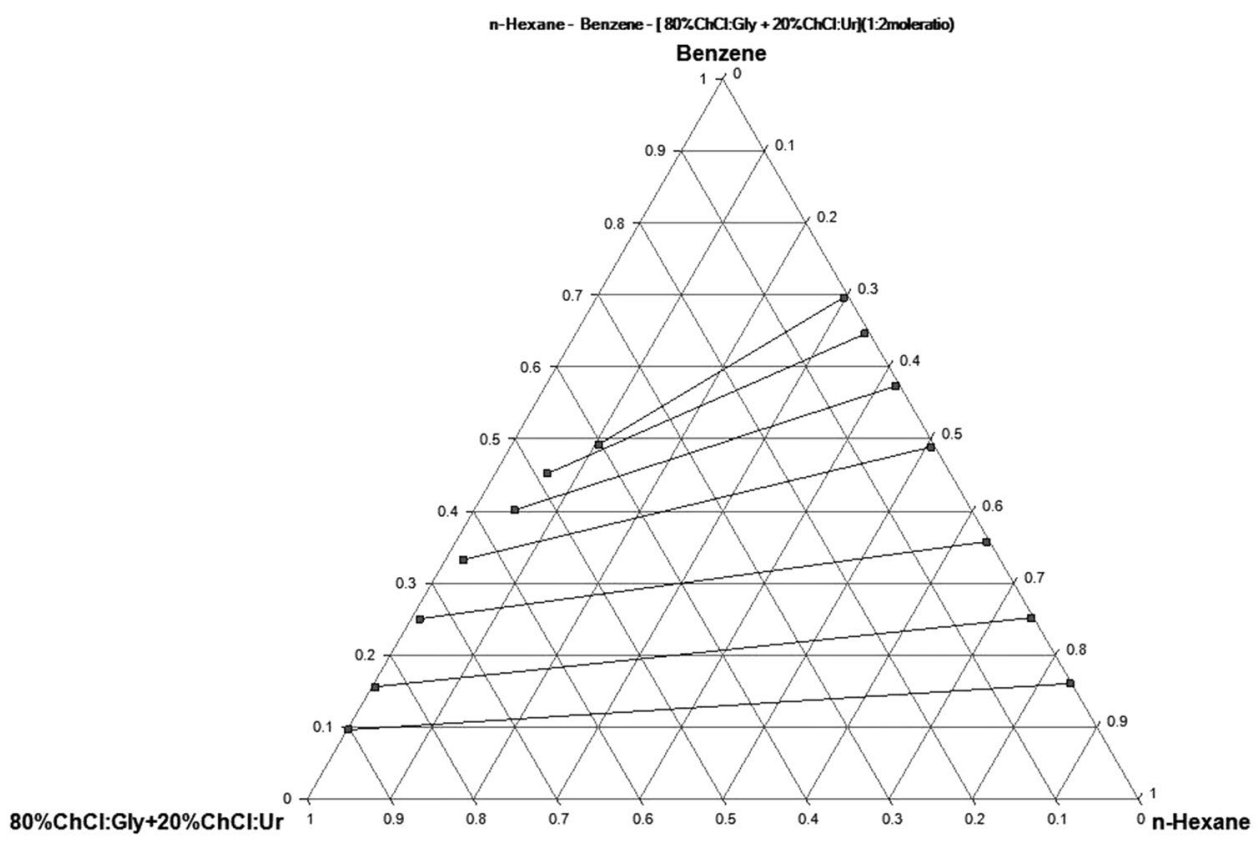

Fig. 13 Experimental tie lines for the system $n$-hexane + benzene $+[80 \% \mathrm{ChCl}: \mathrm{Gly}+20 \% \mathrm{ChCl}$ :Ur $]$ at temperature $303 \mathrm{~K}$ and atmospheric pressure

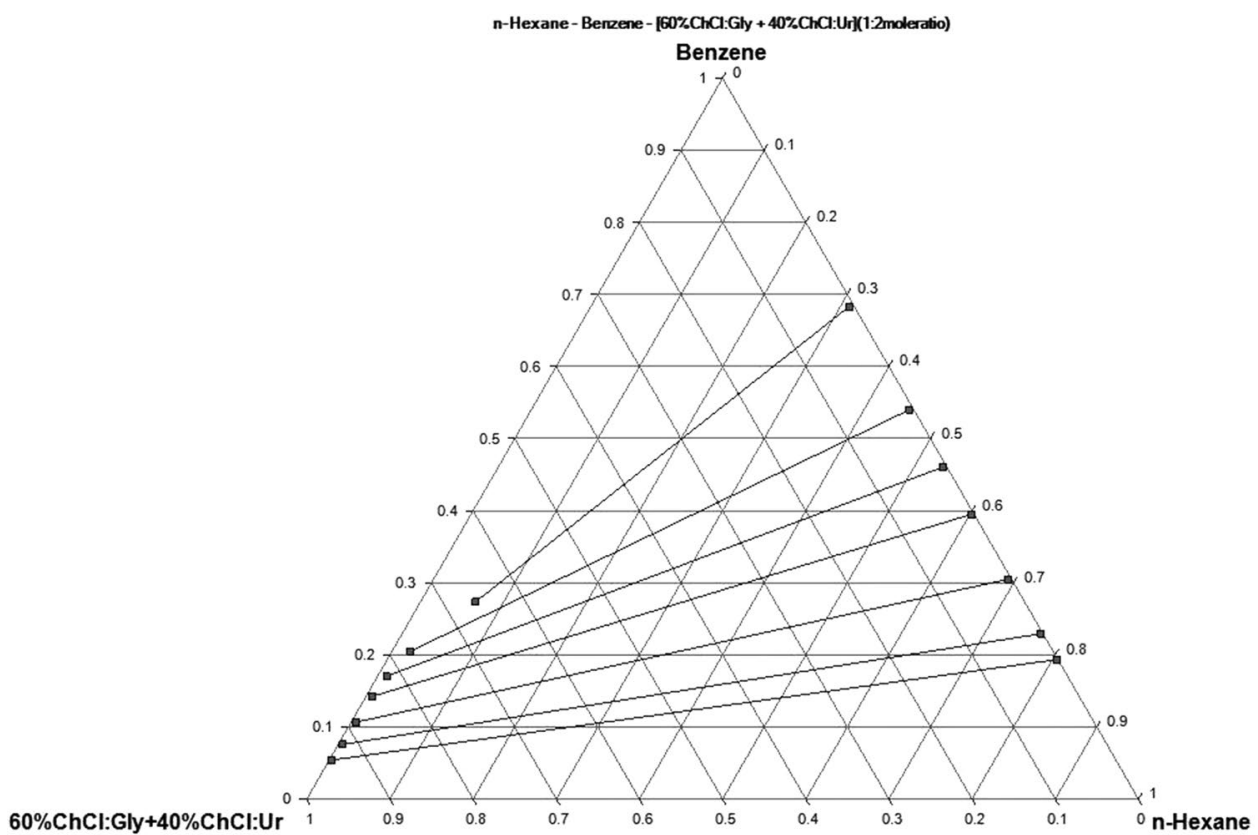

Fig. 14 Experimental tie lines for the system $n$-hexane + benzene $+[60 \% \mathrm{ChCl}: \mathrm{Gly}+40 \% \mathrm{ChCl}$ :Ur] at temperature $303 \mathrm{~K}$ and atmospheric pressure 


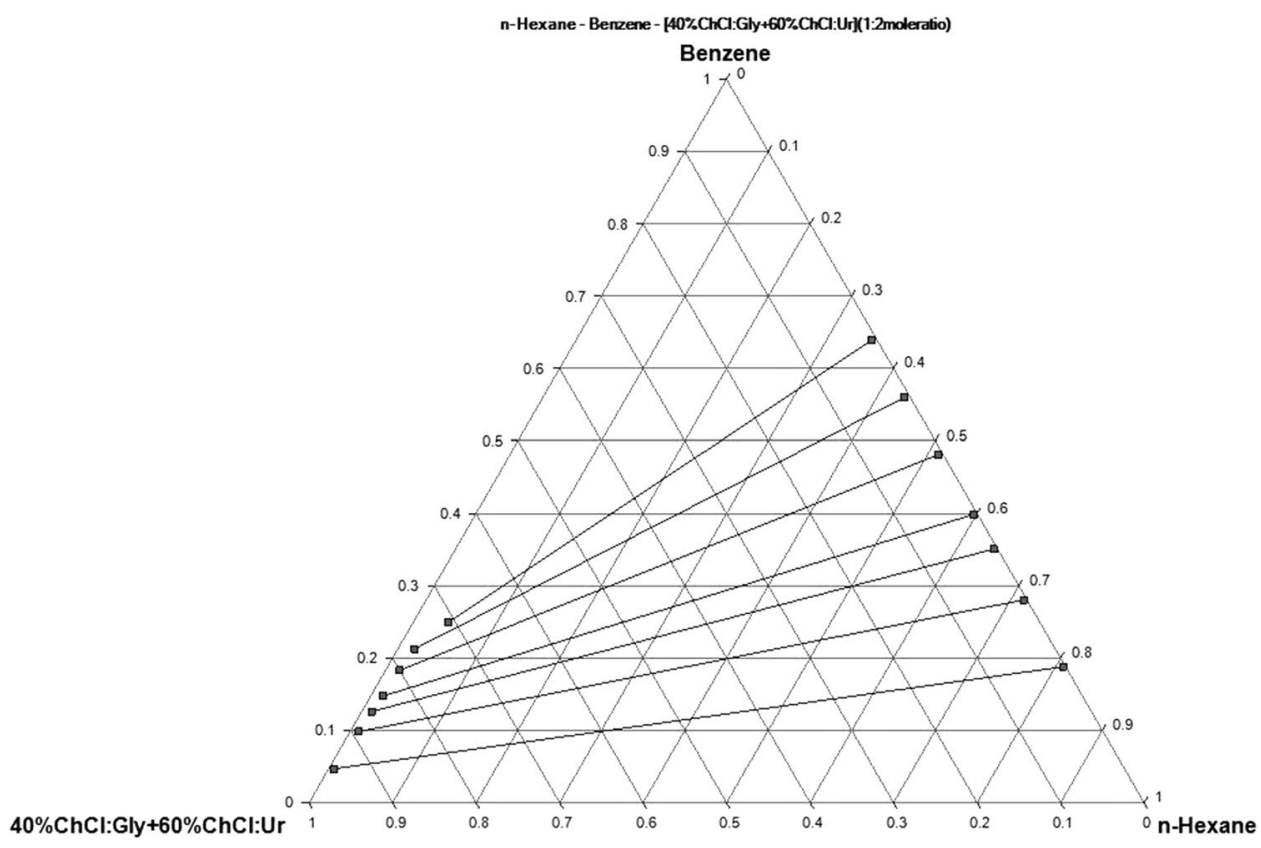

Fig. 15 Experimental tie lines for the system $n$-hexane + benzene $+[40 \% \mathrm{ChCl}: \mathrm{Gly}+60 \% \mathrm{ChCl}: \mathrm{Ur}]$ at temperature $303 \mathrm{~K}$ and atmospheric pressure

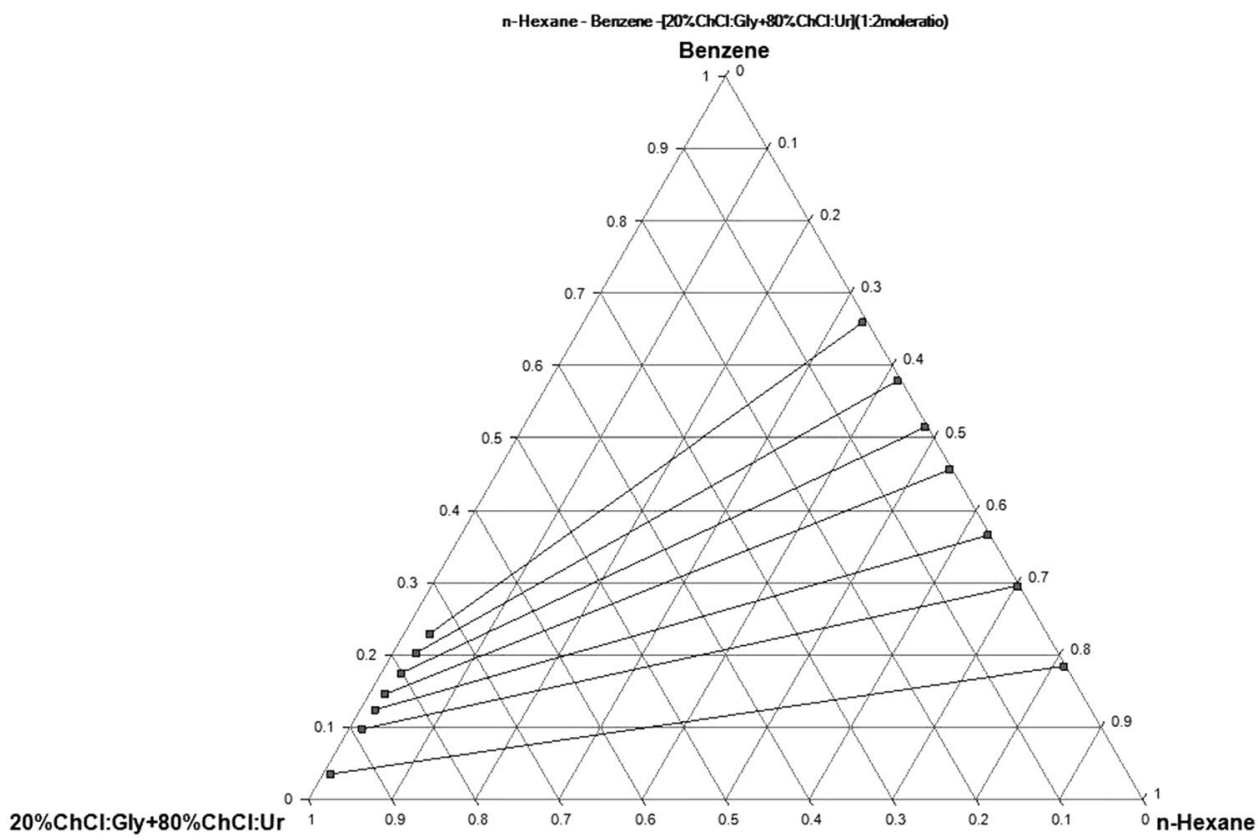

Fig. 16 Experimental tie lines for the system $n$-hexane + benzene $+[20 \% \mathrm{ChCl}: \mathrm{Gly}+80 \% \mathrm{ChCl}$ :Ur $]$ at temperature $303 \mathrm{~K}$ and atmospheric pressure 
Fig. 17 Distribution coefficients as a function of benzene composition in the extract phase for the system $n$-hexane + benzene +DES (glyceline/reline) at temperature $303 \mathrm{~K}$ and atmospheric pressure

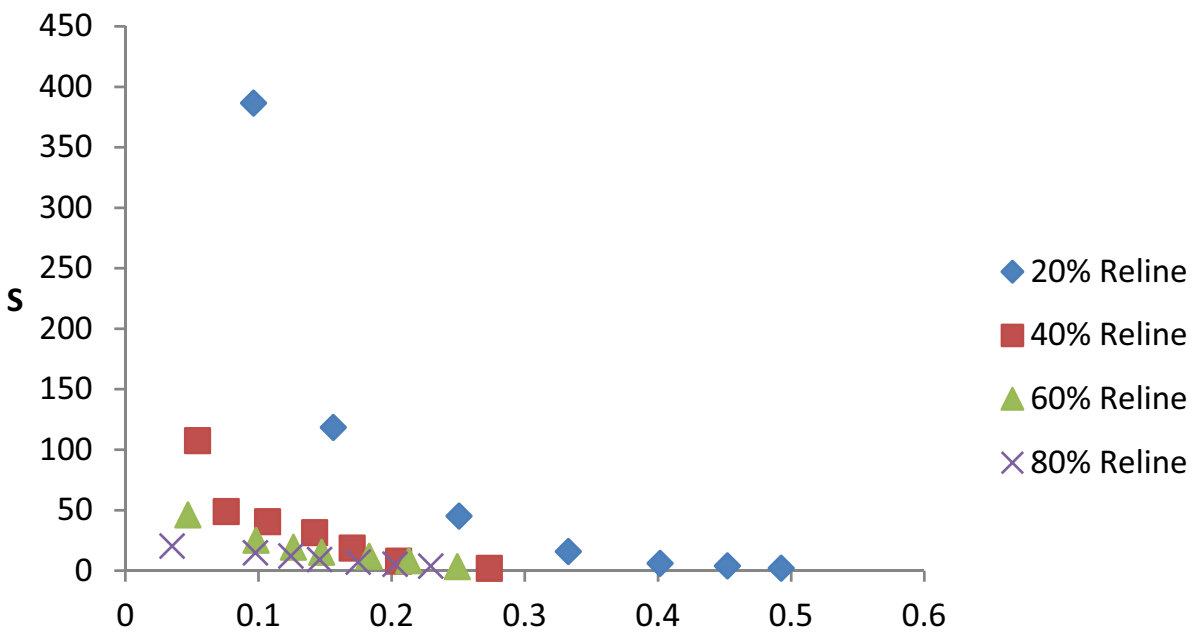

$x_{23}$

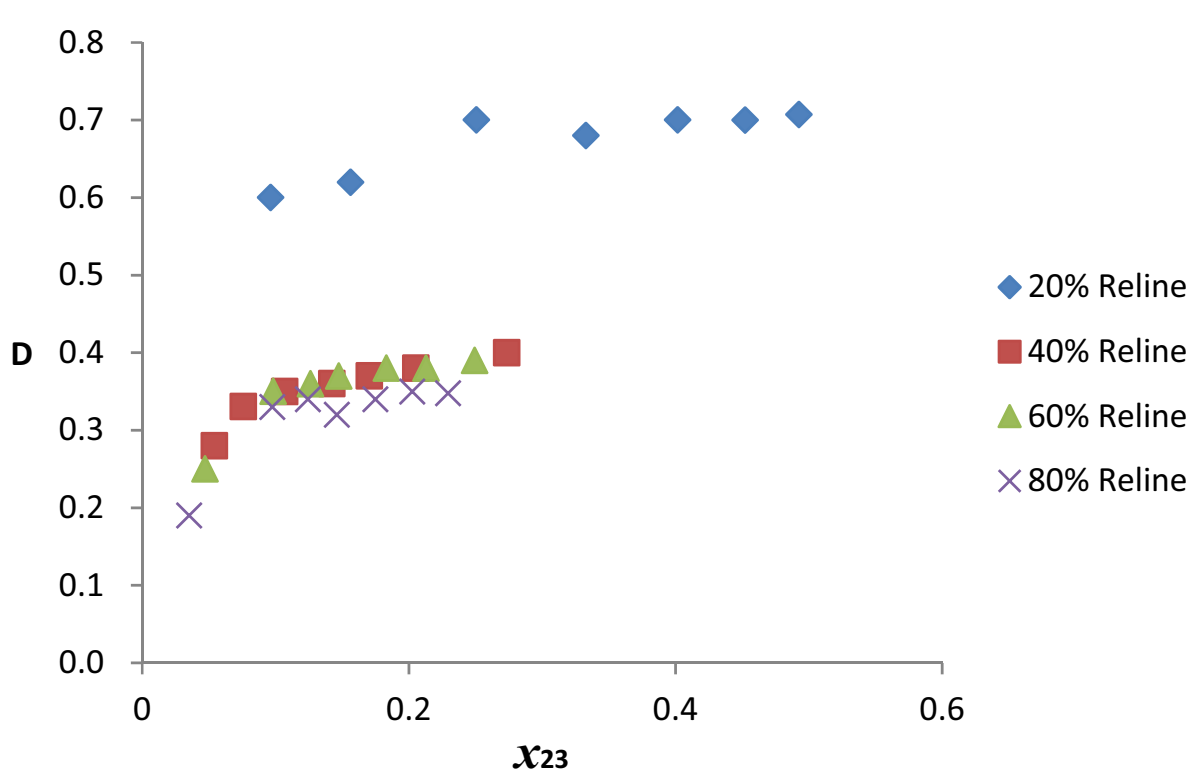

$20 \%$ Reline

$40 \%$ Reline

$60 \%$ Reline

$\times 80 \%$ Reline
Fig. 18 Selectivity as a function of benzene composition in the extract phase for the system $n$-hexane + benzene + DES (glyceline/reline) at temperature $303 \mathrm{~K}$ and atmospheric pressure 
Fig. 19 Extraction efficiency or percent recovery of benzene using various DES

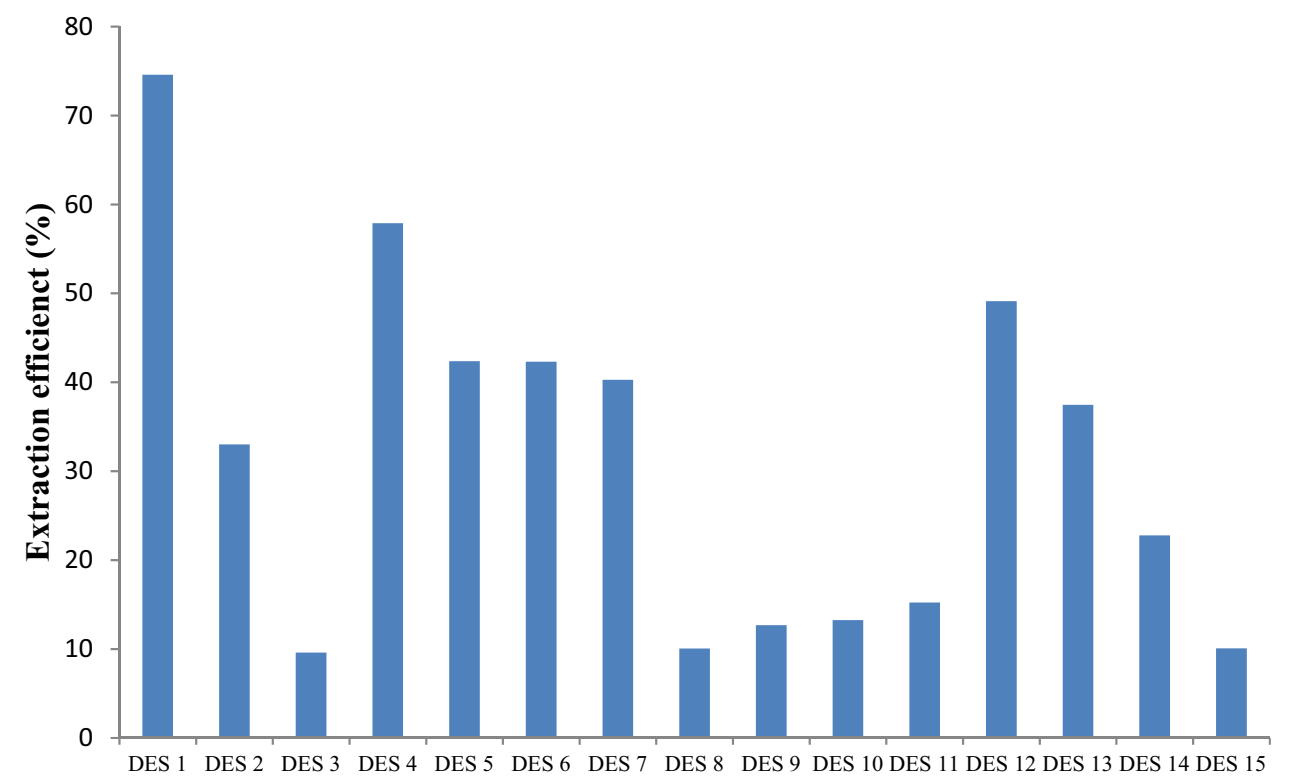

Table 5 Physicochemical properties of glyceline/ethaline mixed DESs as a function of volume percent ethaline

\begin{tabular}{llll}
\hline \% ethaline & Density $\left(\mathrm{g} / \mathrm{cm}^{3}\right)$ & Viscosity $(\mathrm{cP})$ & Refractive index \\
\hline 0 & 1.2600 & 342.12 & 1.4718 \\
20 & 1.2300 & 309.92 & 1.4692 \\
40 & 1.2000 & 230.26 & 1.4667 \\
60 & 1.1700 & 69.75 & 1.4607 \\
80 & 1.1500 & 57.24 & 1.4533 \\
100 & 1.1300 & 38.52 & 1.4507 \\
\hline
\end{tabular}

explored in conjunction with the physicochemical properties of the mixed or hybrid solvents. The mixed DESs exhibit properties according to the ideal mixing rule. Mixture of glyceline with ethaline yielded the much desired reduction in viscosity but at the expense of extraction efficiency. The other two pairs, reline/ethaline and glyceline/reline, may not be desirable considering the negative effect on both extraction efficiency and viscosity relative to reline and glyceline, respectively. The best mixed DES is the glyceline/ethaline at $20 \%$ volume of ethaline, with a drop of $8.55 \%$ in selectivity
Fig. 20 Viscosity, density, and refractive index of glyceline/ ethaline mixed DESs as a function of volume percent ethaline

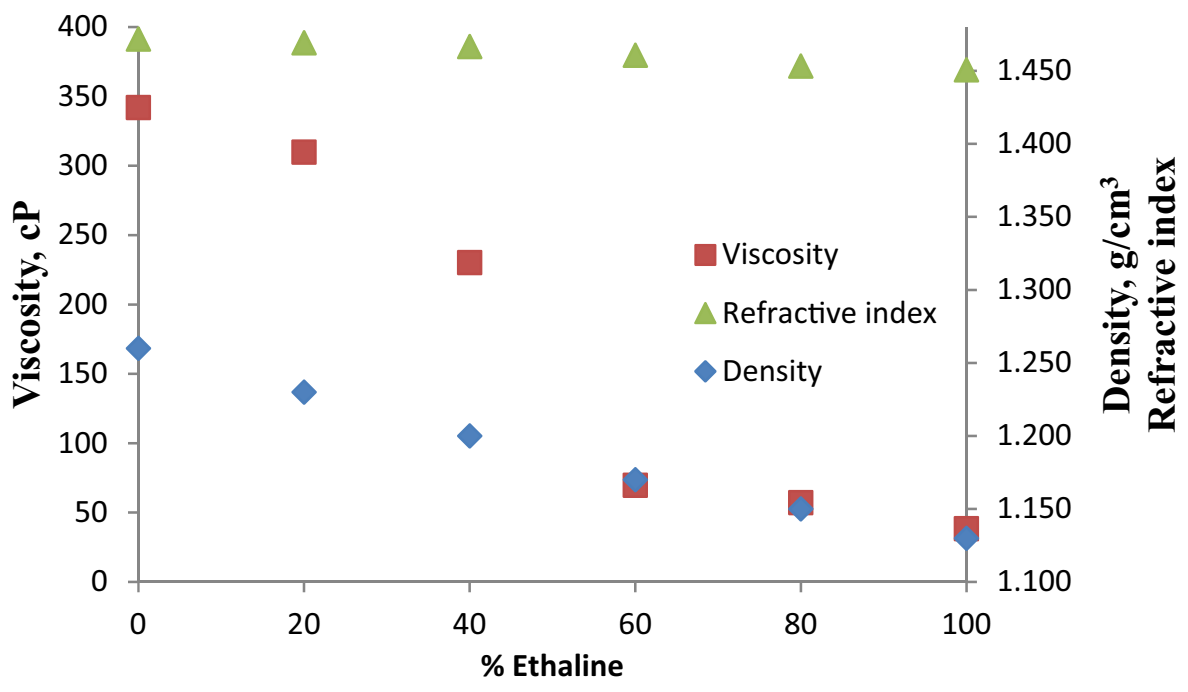


Table 6 Physicochemical properties of reline/ethaline mixed DESs as a function of volume percent ethaline

\begin{tabular}{llll}
\hline \% ethaline & Density $\left(\mathrm{g} / \mathrm{cm}^{3}\right)$ & Viscosity $(\mathrm{cP})$ & Refractive index \\
\hline 0 & 1.27 & 667.28 & 1.4583 \\
20 & 1.25 & 558.15 & 1.4597 \\
40 & 1.22 & 335.62 & 1.4576 \\
60 & 1.18 & 103.21 & 1.4558 \\
80 & 1.16 & 57.54 & 1.4504 \\
100 & 1.13 & 38.52 & 1.4507 \\
\hline
\end{tabular}

Table 7 Physicochemical properties of glyceline/reline mixed DESs as a function of volume percent reline

\begin{tabular}{llll}
\hline \% reline & Density $\left(\mathrm{g} / \mathrm{cm}^{3}\right)$ & Viscosity $(\mathrm{cP})$ & Refractive index \\
\hline 0 & 1.26 & 342.12 & 1.4718 \\
20 & 1.23 & 376.46 & 1.4698 \\
40 & 1.24 & 423.39 & 1.4676 \\
60 & 1.25 & 507.25 & 1.4624 \\
80 & 1.25 & 598.34 & 1.4593 \\
100 & 1.27 & 667.28 & 1.4583 \\
\hline
\end{tabular}

Fig. 21 Viscosity, density, and refractive index of reline/ethaline mixed DESs as a function of volume percent ethaline
Fig. 22 Viscosity, density, and refractive index of glyceline/ reline mixed DESs as a function of volume percent reline
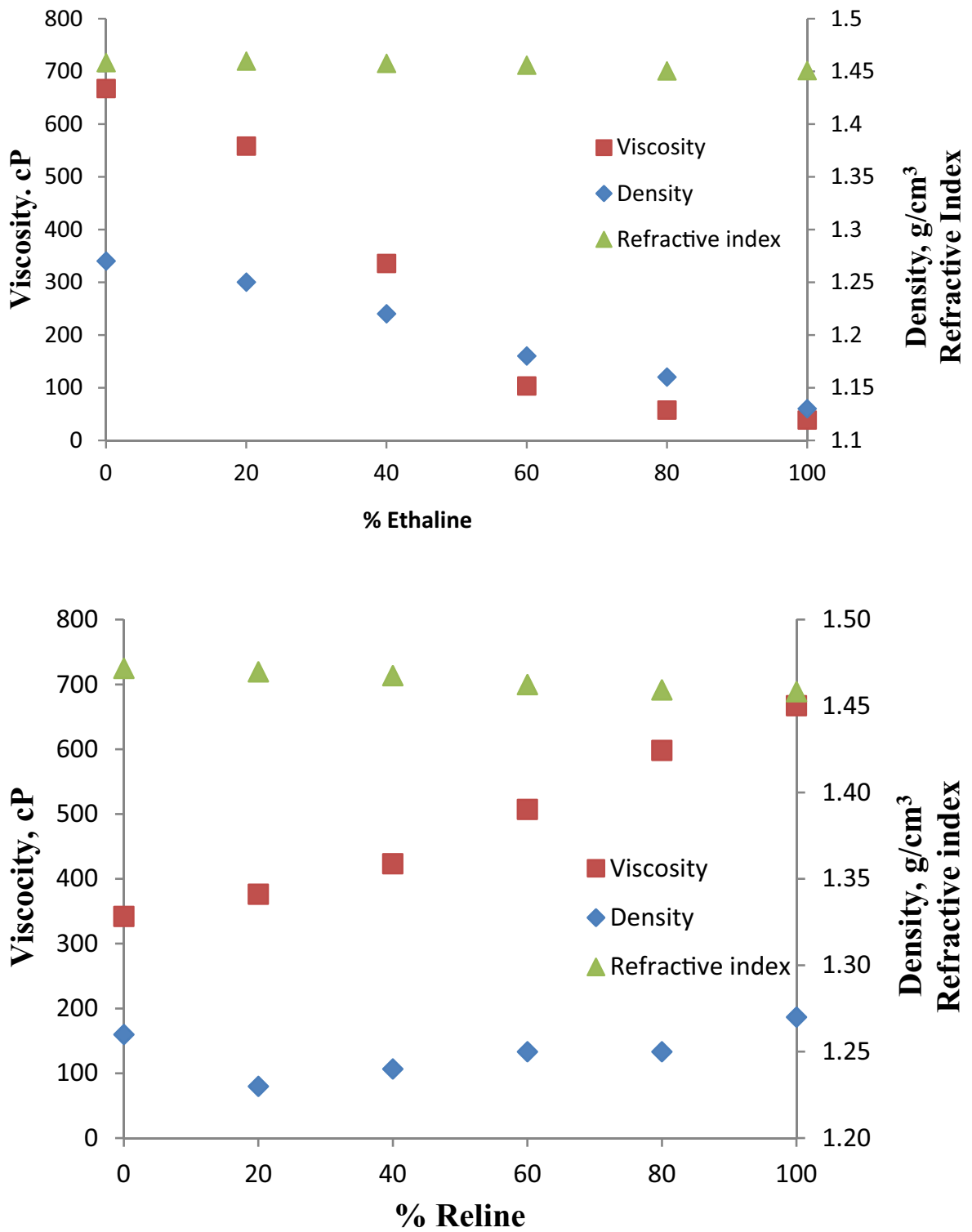
and a decrease of $9.41 \%$ in viscosity relative to neat-glyceline. This mixed DES is superior to sulfolane in terms of extraction performance but inferior in viscosity. There is, therefore, the need to further explore addition of co-solvents to these three deep eutectic solvents for a more impactful reduction in viscosity and better extraction performance. There was an agreement between the performance trend as elucidated by maximum selectivity and percent recovery of benzene, thus validating the use of the former for comparative analysis.

Acknowledgements The authors would like to thank "Professor Ayo Francis Ogunye Trust Foundation, University of Lagos" for the research Grant (VC/OA/E.29/Vol. 9).

Open Access This article is licensed under a Creative Commons Attribution 4.0 International License, which permits use, sharing, adaptation, distribution and reproduction in any medium or format, as long as you give appropriate credit to the original author(s) and the source, provide a link to the Creative Commons licence, and indicate if changes were made. The images or other third party material in this article are included in the article's Creative Commons licence, unless indicated otherwise in a credit line to the material. If material is not included in the article's Creative Commons licence and your intended use is not permitted by statutory regulation or exceeds the permitted use, you will need to obtain permission directly from the copyright holder. To view a copy of this licence, visit http://creativecommons.org/licenses/by/4.0/.

\section{References}

1. Anastas PT, Warner JC (1998) Green chemistry, theory and practice. Oxford University Press, New York

2. Ahluwalia VK, Kidwai M (2004) Basic principles of green chemistry. New trends in green chemistry. Springer, Dordrecht

3. Lapena D, Lomba L, Artel M, Lafuente C, Giner B (2019) The NADES glyceline as a potential green solvent: a comprehensive study of its thermophysical properties and effect of water inclusion. J Chem Thermodyn 128:164-172

4. Garcia G, Aparicio S, Ullah R, Atilhan M (2015) Deep eutectic solvents: physicochemical properties and gas separation applications. Energy Fuels 29(4):2616-2644

5. Smith EL, Abbott AP, Ryder KS (2014) Deep eutectic solvents (DESs) and their applications. Chem Rev 114(21):11060-11082

6. Bystrzanowska M, Tobiszewski M (2021) Assessment and design of greener deep eutectic solvents - a multicriteriadecision analysis. J Mol Liq 321:114878

7. Lapena D, Errazquin D, Lomba L, Giner B (2021) Ecotoxicity and biodegradability of pure and aqueous mixtures of deep eutectic solvents: glyceline, ethaline, and reline. Environ Sci Pollut Res 28(7):8812-8821

8. Taghizadeh M, Taghizadeh A, Vatanpour V, Ganjali MR, Reza M (2021) Deep eutectic solvents in membrane science and technology: fundamental, preparation, application, and future perspective. Sep Purif Technol 258(Part 2):118015

9. Zafarani-Moattar MT, Shekaari H, Dizaj AS (2020) Investigation of solute-solvent intereactions in binary and quaternary solutions containing lithium perchlorate, propylene carbonate, and the deep eutectic solvent (choline chloride/ethylene glycol) at $T=(298.15$ to 318.15) K. J Mol Liq 319:114090
10. Usman MA, Fagoroye OK, Ajayi TO, Kehinde AJ (2020) Ternary liquid-liquid equilibrium data for $n$-hexane-benzene-DES (choline chloride/ethylene glycol, choline chloride/glycerol, choline chloride/urea) at $303 \mathrm{~K}$ and $101.3 \mathrm{kPa}$. Appl Petrochem Res 10(3):125-137

11. Usman MA, Fagoroye OK, Ajayi TO, Kehinde AJ (2021) ASPEN plus simulation of liquid-liquid equilibria data for the extraction of aromatics from waste tyre pyrolysis gasoline using organic and deep eutectic solvents: a comparative study. Appl Petrochem Res. https://doi.org/10.1007/s13203.020.00262-8

12. AlOmar MK, Hayyan M, Alsaadi MA, Akib S, Hayyan A, Hashim MA (2016) Glycerol-based deep eutectic solvents: physical properties. J Mol Liq 215:98-103

13. Ibrahim RK, Hayyan M, Alsaadi MA, Ibrahim S, Hayyan A, Hashim MA (2019) Physical properties of ethylene glycol-based deep eutectic solvents. J Mol Liq 276:794-800

14. Yue D, Jia Y, Yao Y, Sun J, Jing Y (2012) Structure and electrochemical behavior of ionic liquid analogue based on choline chloride and urea. Electrochim Acta 65:30-36

15. Canales RI, Brennecke JF (2016) Comparison of ionic liquids to conventional organic solvents for extraction of aromatics from aliphatics. J Chem Eng Data 61(5):1685-1699

16. Garcia S, Larriba M, Garcia J, Torrecilla JS, Rodriguez F (2012) Liquid-liquid extraction of toluene from $n$-heptane using binary mixture of $\mathrm{N}$-butylpyridinium tetrafluoroborate and $\mathrm{N}$-butylpyridinium bis(trifluoromethylsulfonyl)imide ionic liquids. Chem Eng J 180:210-215

17. Alkhaldi KHAE, Al-Jimaz AS, AlTuwaim MS (2019) Liquid extraction of toluene from heptanes, octane, or nonane using mixed ionic solvents of 1-ethyl-3-methylimidazolium methylsulfate and 1-hexyl-3-methylimidazolium hexafluorophosphate. J Chem Eng Data 64(1):169-175. https://doi.org/10.1021/acs.jced. $8 \mathrm{~b} 00669$

18. Guo Y, Shi F, Shu Q, Yue X, Wang C, Tao L, Li J (2020) Liquidliquid equilibrium for $n$-hexane + benzene + sulfolane, + 1-ethyl3-methylimidazolium bis(trifluoromethylsulfonyl)imide ([EMIM] $\left.\left[\mathrm{NTf}_{2}\right]\right)$, + 1-ethyl-3-methylimidazolium ethylsulfate ([EMIM] $\left.\left[\mathrm{EtSO}_{4}\right]\right)$ and the mixtures of [EMIM] $\left[\mathrm{NTf}_{2}\right]$ and $[\mathrm{EMIM}]\left[\mathrm{EtSO}_{4}\right]$. Fluid Phase Equilib. https://doi.org/10.1016/j.fluid.2020.112882

19. Mjalli FS, Ahmed OU (2017) Ethaline and glyceline binary eutectic mixtures: characteristics and intermolecular interactions. AsiaPac J Chem Eng 12(2):313-320

20. Mjalli FS, Ahmed OU (2015) Characteristics and intermolecular interaction of eutectic binary mixtures: reline and glyceline. Korean J Chem Eng 33:337-343

21. Mjalli FS, Ahmed OU (2016) Physical properties and intermolecular interaction of eutectic solvents binary mixtures: reline and ethaline. Asia-Pac J Chem Eng 11(4):549-557

22. Sandier SI, Orbey H (2000) 9 Mixing and combining rules. Exp Thermodyn 5:321-357

23. Gernert J, Jager A, Span R (2014) Calculations of phase equilibria for multi-component mixtures using highly accurate Helmholtz energy equations of state. Fluid Phase Equilib 375:209-218

24. Dehaghani AHS (2017) New insight into prediction of phase behavior of natural gas hydrate by different cubic equations of state coupled with various mixing rules. Pet Sci 14:780-790

25. Pisarev V, Mistry S (2019) Volume-based mixing rulesfor viscosities of methane $+n$-butane liquid mixtures. Fluid Phase Equilib 484:98-105

Publisher's Note Springer Nature remains neutral with regard to jurisdictional claims in published maps and institutional affiliations. 